Portland State University

PDXScholar

Civil and Environmental Engineering Master's

Project Reports

Summer 2014

\title{
Analysis of Landsat Satellite Data to Monitor Water Quality Parameters in Tenmile Lake, Oregon
}

Michael T. Waxter

Portland State University

Follow this and additional works at: https://pdxscholar.library.pdx.edu/cengin_gradprojects

Part of the Water Resource Management Commons

Let us know how access to this document benefits you.

\section{Recommended Citation}

Waxter, Michael T., "Analysis of Landsat Satellite Data to Monitor Water Quality Parameters in Tenmile Lake, Oregon" (2014). Civil and Environmental Engineering Master's Project Reports. 2.

https://doi.org/10.15760/CEEMP.35

This Project is brought to you for free and open access. It has been accepted for inclusion in Civil and Environmental Engineering Master's Project Reports by an authorized administrator of PDXScholar. Please contact us if we can make this document more accessible: pdxscholar@pdx.edu. 
Analysis of Landsat Satellite Data to Monitor Water Quality Parameters in Tenmile Lake, Oregon

BY

\begin{abstract}
Michael Waxter
A research project report submitted in partial fulfillment of the requirement for the degree of

MASTER OF SCIENCE

IN

CIVIL AND ENVIRONMENTAL ENGINEERING
\end{abstract}

Project Advisor:

Dr. Stefan Talke

Portland State University

(C)2014 


\section{ACKNOWLEDGMENTS}

This study benefited from several organizations and people.

- The National Aeronautics and Space Administration (NASA) developed and runs the LANDSAT satellite

- United States Geological Survey (USGS) provided the satellite data.

- Tenmile Lake Basin Partnership (TLBP) provided the in-situ lake data.

- Dr. Stefan Talke provided guidance and advice.

- The Civil and Environmental Engineering department at Portland State University has supported my work. 


\begin{abstract}
The health of North and South Tenmile Lakes in coastal Oregon has declined since the introduction of invasive species of fish and plant life in the 1920s. The lakes are now on the Federal Clean Water Act list of impaired water bodies due, in part, to a lack of dissolved oxygen and Hazardous Algae Blooms (HAB) blooms that occur during June through September. In this report we discuss the possibility of detecting and monitoring these blooms using satellite measurements of water surface color. In-situ measurements obtained from the Tenmile Lakes Basin Partnership were used to calibrate reflectance from the Thematic Mapper on the Landsat 5 satellite. Results show a good linear correlation between turbidity and radiance, which are inversely related in algal dominated lakes. Additionally, a correlation between biovolume and reflectance was obtained. Spatial patterns of turbidity and biovolume are observed, with large concentrations observed in lake areas with large residence times. The comparatively lowest concentrations are observed along the probable pathway of cleaner water input by creeks into the lake. However, the ability to predict turbidity and biovolume from satellite reflectance data is currently complicated by the lack of coincident in-situ and satellite data, and the limited number of spectral bands available to separate turbidity from different species of bacteria and algae.
\end{abstract}




\section{TABLE OF CONTENTS}

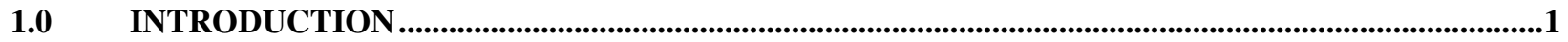

2.0 METHODS

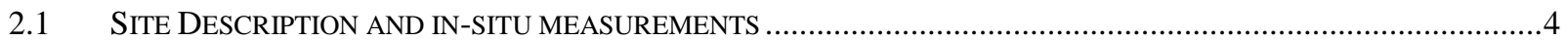



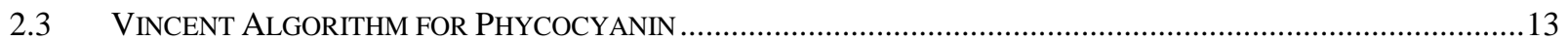

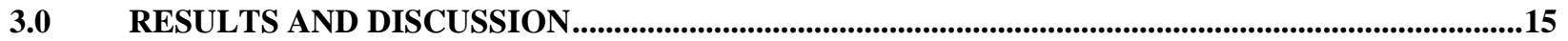

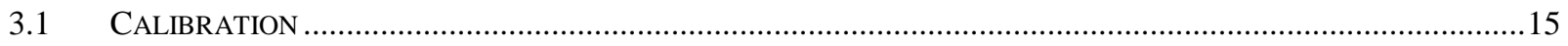

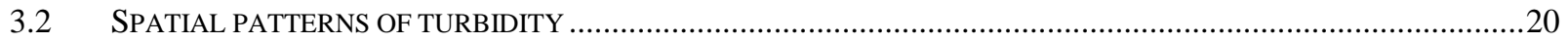

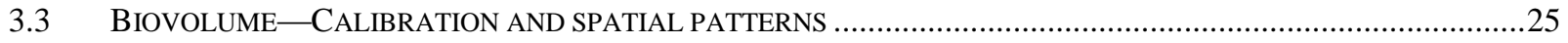

3.4 COMPARISON BETWEEN SATELLITE DATA DigITAL NUMBERS AND RADIANCE ..........................................30

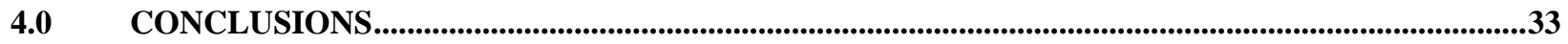

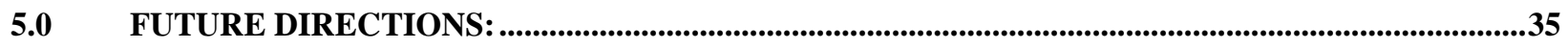

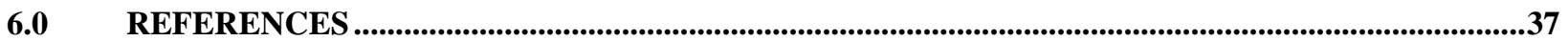




\section{LIST OF TABLES}

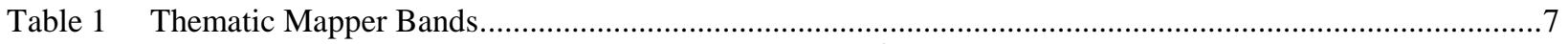

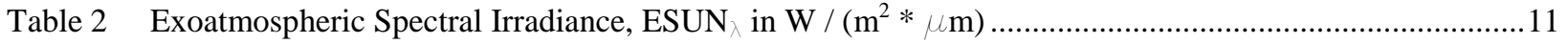

Table 3 Earth-Sun Distance in Astronomical Units for Use in Equation 3 ......................................................12

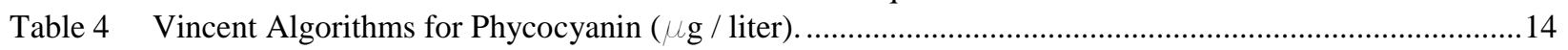

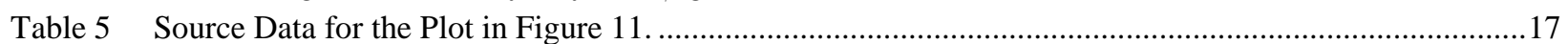

Table 6 Summary of R-Squared Values for Data Type for Turbidity versus Thematic Mapper Band. .....................31 


\section{LIST OF FIGURES}

Figure 1 Topographic map of Tenmile Lake, known more commonly as South Tenmile Lake.............................1

Figure 2 Topographic map of North Tenmile Lake including freshwater inlets..............................................2

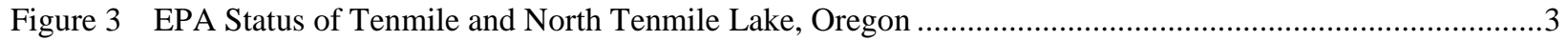

Figure 4 Sample Site Locations for North and South Tenmile Lake. ..............................................................6

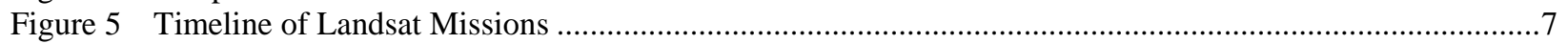

Figure 6 An example jpeg from Landsat 5 Path 47 Row 30 from July 11, 2007...........................................

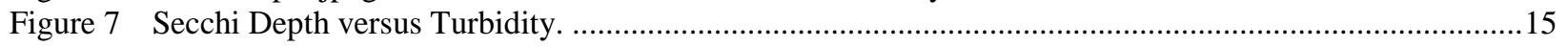

Figure 8 Bin Averaged Secchi Depth vs Turbidity............................................................................... 16

Figure 9 Plot of Combined Turbidity versus TM Band 1 DNN for all data points for all sites. ...........................17

Figure 10 Plot of Combined Turbidity versus TM Band 1 DNN's without Site N11 data. ...................................18

Figure 11 Bin Averaged - Combined Turbidity versus TM Band 1 DNN without N11......................................19

Figure 12 Bin Averaged - Combined Turbidity versus TM Band 1 DNN for all sites........................................20

Figure 13 MatLab pcolor plot of Turbidity on Tenmile Lake for June 15, 2004 using the curve from Turbidity versus Band 1 with exclusion of Site N11 .........................................................................21

Figure 14 MatLab pcolor plot of Turbidity on Tenmile Lake for August 18, 2004. Based on linear Turbidity versus

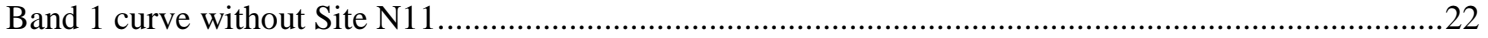

Figure 15 Combined Turbidity vs TM Band 1 DNN by Site ......................................................................23

Figure 16 Plot for a Color Classification Scheme for Lakes....................................................................24

Figure 17 Binned Average for $\log _{10}(\mathrm{TBV})$ vs TM Band 1 Reflectance for All Sites...........................................26

Figure 18 Binned Average for $\log _{10}(\mathrm{TBV})$ vs TM Band 2 Reflectance for All Sites........................................26

Figure 19 Binned Average for $\log _{10}(\mathrm{BGBV})$ vs TM Band 1 Reflectance for All Sites.....................................27

Figure 20 Binned Average for $\log _{10}(\mathrm{BGBV})$ vs TM Band 2 Reflectance for All Sites...................................27

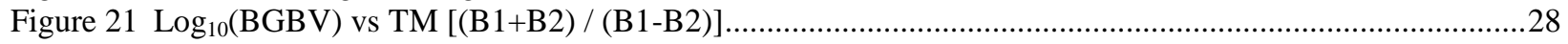

Figure 22 Chlorophyll a concentration vs TM Band 2 Reflectance for Site S8...............................................29

Figure 23 Chlorophyll a concentration vs TM Band 2 Reflectance for Site N11 ..............................................29

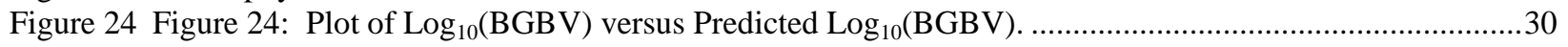

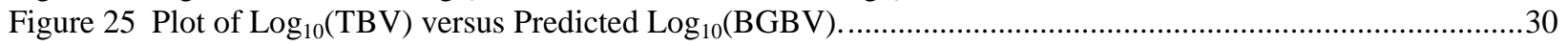

Figure 26 R-Squared for Turbidity versus Band (1, 2, or 3 ) for different data types...........................................31

Figure 27 Normalized Radiance for different data types for each band considered. ...........................................32

Figure 28 An example absorption spectrum for water with a cyanobacteria presence. ......................................35 


\subsection{INTRODUCTION}

South Tenmile Lake and North Tenmile Lake are both located in the coastal mountain range of central Oregon near Lakeside, Oregon. The lakes are connected by a canal, so water from both empties into the Pacific Ocean via Tenmile Creek. Each lake is fed by multiple streams including Shutter Creek, Big Creek, Adams Creek, Johnson Creek and Benson Creek (Figures 1 and 2). North and South Lakes together are one of the largest lakes on the Oregon Coast. The shoreline of both lakes is approximately 23.6 miles, but the name originated from the fact that the lakes are located about ten miles south of Winchester Bay. Both lakes are considered shallow with a maximum depth of about 35 feet and an average depth of about 7 feet. Seasonal shallow water aquatic vegetation (SAV) is present at the end of multiple arms. Lake depth is decreasing due to sediment input from creeks and erosion from fringing land. The bottom composition is a mixture of inorganic sediment and rich organic matter washed in from the highly productive drainage area. Tenmile Lakes are considered eutrophic, with nitrates and phosphates supplied during inflow events. Nutrients are also recycled by sediment erosion and resuspension, which can happen through wind waves and large creek-flow events. The shoreline is mostly privately owned by people who rely on the lakes as their primary source of water.

Sewage from these houses is another probable source of nutrient input.

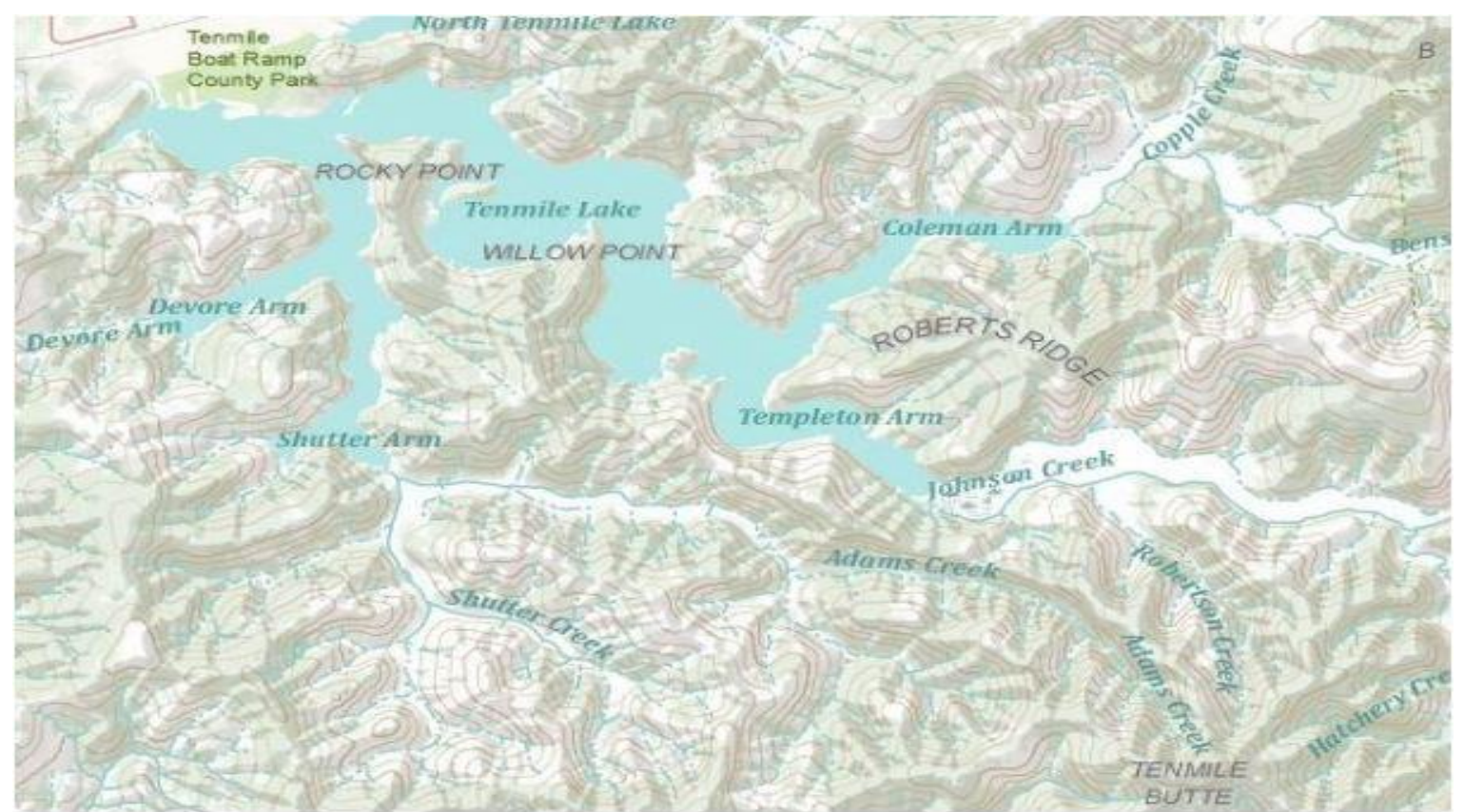

Figure 1 Topographic map of Tenmile Lake, known more commonly as South Tenmile Lake.

Note the number of freshwater inlets. From ArcGIS North American Water Polygons 


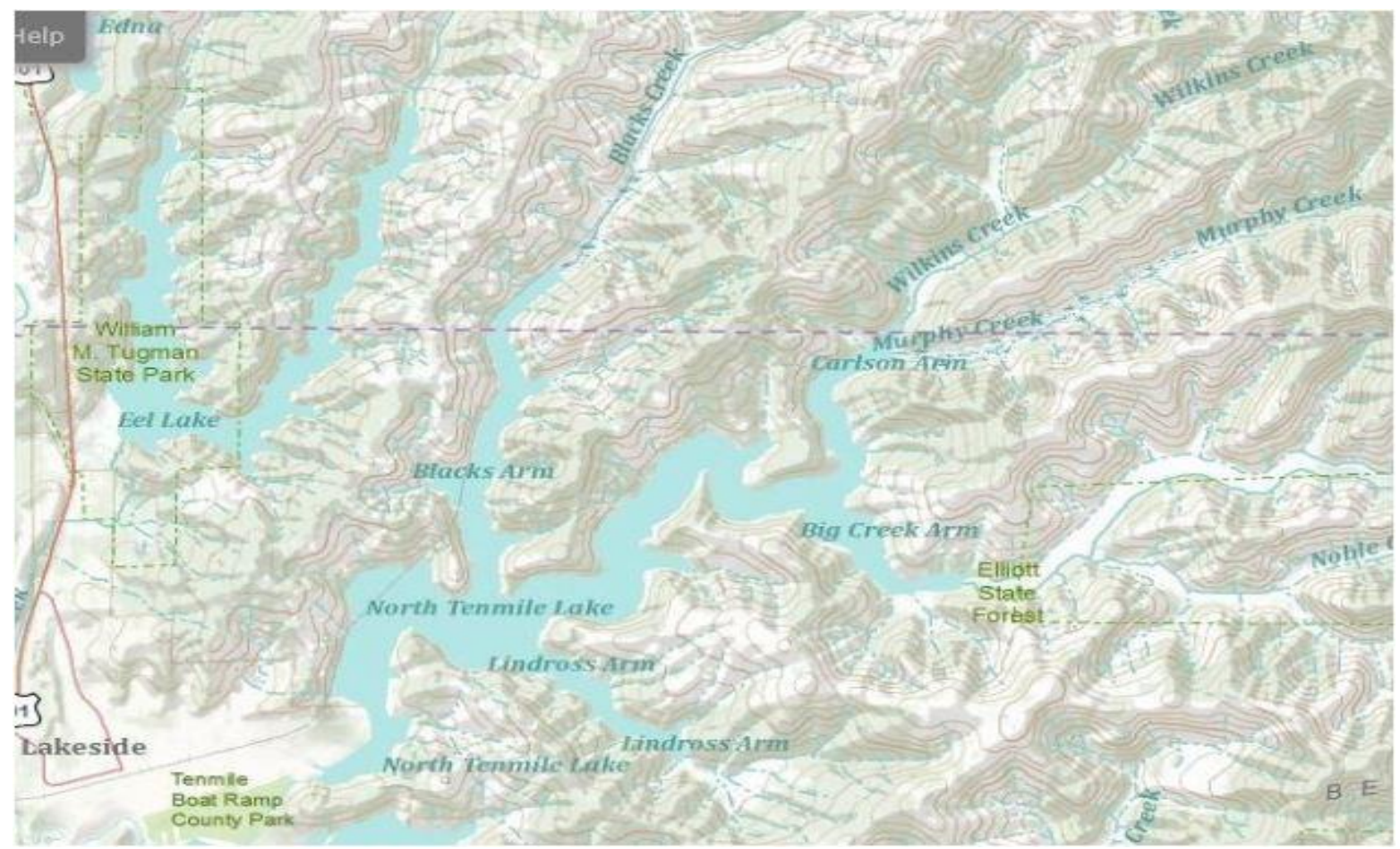

Figure 2 Topographic map of North Tenmile Lake including freshwater inlets.

From ArcGIS North American Water Polygons

The lakes are also heavily utilized for recreational fishing. The original species include Cutthroat Trout, Silver Salmon, and Steelhead, which passed through the productive lakes to spawn in the tributary streams (Atlas of Oregon Lakes, 2014). Health of the lakes has been on the decline since the 1920s when invasive species of fish and plant life, including yellow perch and Elodea, began to be introduced. The lakes are now on the Federal Clean Water Act list of impaired water bodies due, in part, to lack of dissolved oxygen and high Chlorophyll a concentrations during July through September (Figure 3). Large cyanobacteria, or blue-green algae, blooms occur during these summer months. These Hazardous Algae Blooms (HAB's) are an increasing problem globally in all types of water bodies due to increased eutrophication. For example, the Baltic Sea shows signs of cyanobacteria blooms yearly during summer months (Kahru et al. 1994). Many cyanobacteria produce toxins including hepatotoxins, neurotoxins, and cytotoxins. Toxins are either released into the water throughout the life of the bacteria, or the toxins are released into the water after the cell is lysed. These toxins are referred to as exotoxins and endotoxins, respectively. In Tenmile Lakes, Oregon, five species of cyanobacteria are problematic: Microcystis aeruginosa, Anabaena flos-aquae, Aphanizomenon flos-aquae, Woronichinia spp, and Gloeotrichia echinulata (TLBP, 2012). The two most problematic 
bacteria on Tenmile Lakes, Microcystis and Anabaena, produce isomers of the toxins Anatoxin and Microcystin. Microcystin is both a toxin and a mutagen. A common isomer of Anatoxin, Anatoxin a, is historically referred to as the "Very Fast Death Factor". Ingestion of Anatoxin a can cause death within minutes.

Watershed Assessment, Tracking \& Environmental Results

Recent Additions I Contact Us Search: OAll EPA O This Area Go

Waterbodies matching search criteria: Area equals "OR" and waterbody name contains "Tenmile lake"

\begin{tabular}{|c|c|c|c|c|c|c|c|c|c|}
\hline & & \multirow[b]{2}{*}{$\begin{array}{c}\frac{\text { Most Current Data }}{\text { Available }} \\
\end{array}$} & \multirow[b]{2}{*}{ Lecation } & \multirow[b]{2}{*}{ Map } & \multirow[b]{2}{*}{$\frac{\text { Waterbody }}{\text { Ivpe }}$} & \multirow[b]{2}{*}{ Size } & \multirow[b]{2}{*}{ Unit } & \multirow[b]{2}{*}{ Status } & \multirow[b]{2}{*}{$\begin{array}{c}\frac{\text { State TMDL Development }}{\underline{\text { Status }}} \\
\end{array}$} \\
\hline \begin{tabular}{|l|} 
Waterbody Name \\
\end{tabular} & Waterbody ID & & & & & & & & \\
\hline North Tenmile Lake & OR_1241456435885_O_O & 2006 & $\begin{array}{l}\text { Coos: } \\
17100304\end{array}$ & $\begin{array}{c}\text { Data } \\
\text { Unavailable }\end{array}$ & Freshwater Lake & 846.0 & Acres & Good & \\
\hline North Tenmile Lake / North Tenmile Lake & OR1241613435770_1241456435885_0_4.5 & 2006 & O To 4.5 Miles & $\begin{array}{c}\text { Data } \\
\text { Unavailable }\end{array}$ & Lake & & Acres 1 & Impaired & \\
\hline \begin{tabular}{|l} 
North Tenmile Lake / North Tenmile Lake: Mm \\
$0-4.5$
\end{tabular} & OR_1241613435770/1241456435885_0_4.5 & 2006 & $\begin{array}{l}\text { Coos: } \\
17100304\end{array}$ & $\begin{array}{c}\text { Data } \\
\text { Unavailable } \\
\end{array}$ & Freshwater Lake & & Acres & Impaired & \\
\hline Tenmile Lake / Tenmile Lake & OR1241746435728_1241367435617_0_5 & 2006 & 0 To 5 Miles & Waterbody Map & Lake & & Acres & Impaired & \\
\hline Tenmile Lake / Tenmile Lake: Mm 0-5 & OR_1241746435728/1241367435617_0_5 & 2006 & $\begin{array}{l}\text { Coos: } \\
17100304\end{array}$ & $\begin{array}{c}\text { Data } \\
\text { Unavailable }\end{array}$ & Freshwater Lake & 1,18 & Acres & Impaired & \\
\hline
\end{tabular}

Figure 3 EPA Status of Tenmile and North Tenmile Lake, Oregon

Retrieved from http://iaspub.epa.gov/waters10/attains_index.search_wb?p_area=OR\&p_cycle=2006

Because of legislation and citizen concern, an extensive water sampling program has been undertaken by Tenmile Lakes Basin Partnership (TLBP) since 1998 to test a variety of water quality parameters on and around the lake. This compilation of water quality data provides a unique opportunity to investigate the use of remotely sensed satellite data to monitor inland freshwater quality. Satellite data may be able to provide a greater amount of spatial information at an improved cost compared to spot sample grabs. Moreover, satellite-based measurements may provide a mechanism for early detection of blooms and/or the detection of hot-spots in unmeasured locations. In this report we investigate the possibility of using LANDSAT satellite data to describe spatial patterns of turbidity and biovolume in Tenmile lakes. 


\subsection{METHODS}

\subsection{Site Description and in-situ measurements}

Invasive species were introduced sometime in the 1920s, and the quality of the lake by 1938 resulted in a limited sampling and investigation program. The program expanded in 1954 with renewed interest in lake water quality (Atlas of Oregon Lakes, 2014). Data for this study was obtained from the Tenmile Lakes Basin Partnership (TLBP) in Lakeside, Oregon. Both biological and physical data has been collected between 2004 and 2012. Unfortunately, virtually all of the sampling occurred during the summer months when an algal bloom existed. Sampling and processing was performed by employees of TLBP, using methods established by and generally in agreement with Oregon Department of Environmental Quality (DEQ) Water Quality Monitoring Methods (Oregon DEQ Water Quality Monitoring: Technical Guide Book, 1999). The data was collected at approximately 2 week intervals, but is not necessarily continuous. For example, turbidity was only occasionally measured between 2006 and 2012. Similar inconsistencies are observed in biological data, with biovolume initially measured by species, and later by class.

Biological data consists of algal data along with limited Chlorophyll a and toxin concentrations. Chlorophyll a and toxin concentration are typically reported in $\mu \mathrm{g} / \mathrm{L}$, or ppb. Biovolume is reported in $\mu \mathrm{m}^{3} / \mathrm{ml}$. It is determined by counting the numbers of each bacteria type in a volume of water. A volume for each cell type and total volume for the total number each cell type is then calculated based upon volume formulas for each type of cell shape and measured size. Biovolume is also sometimes reported as the volume of all algae in a given amount of water. Density is another term used in for algal studies, and it refers to just the number of cells or cell colonies in a given amount of water. The size of the bacteria is not determined in density studies. Specific cell type biovolumes are often determined in order to obtain a Palmer Index. The Palmer Index indicates water quality by the species of bacteria present in a waterbody (Palmer, 1969). From studies of Tenmile Lakes, it was determined that the two most problematic bacteria are Microcystin aeruginosa and Anabaena flos-aqua. 
Physical data includes, but is not limited to, $\mathrm{pH}$, temperature, dissolved oxygen, turbidity, Secchi depth, specific conductivity, and a range of chemical concentrations: Silicate, Nitrate, Nitrite, Ammonium, and also total Nitrogen and total Phosphorus.

Sampling occurred between the hours of 8:30 am and 1:30 pm. Secchi depth, $\mathrm{pH}$, temperature, dissolved oxygen, and specific conductivity were determined in-situ at each site before samples were taken from a boat with a 3.5 liter tube water sampler. While in-situ samples are all performed with a single or a combined meter lowered into the water for a measurement, the samples taken for later analysis come from a tube sampler that represent the contents of the top one meter of the water column. Three samples were taken from each sample site and placed in a labelled container. The samples were then mixed to homogeneity after arriving at TLBP (in Lakeside), and aliquots taken for external laboratory analysis on the remaining physical and biological parameters. Turbidity was estimated "in house" at TLBP after manually stirring. A number of brands of $\mathrm{pH}$, temperature, dissolved oxygen, specific conductivity, and turbidity meters are available commercially, but calibration of the meters prior to each use is more important than the brand used.

Figure 4 shows a map of sample site locations. The four most continuous sample site ID's are S3, S8, N11, and N16. These represent two locations in each lake in areas of significance. For example, $\mathrm{S} 3$ is located on Templeton Arm, where a large number of salmonids spawn yearly. N11 is located near North Tenmile Lake Marina, a heavily populated location with boat traffic and potential pollution. S8 is located southeast from the town of Lakeside near the boat launch ramps and the canal joining North and South Lakes. It is the closest sample site to Tenmile Creek, and has water from both lakes pass nearby on its way into Tenmile Creek and then the Pacific Ocean. Sample site N16 is located on North Tenmile Lake just south of the channel that leads to the canal. While N16 is not too close to the canal, it is still on the main section of lake prior to the canal. Sites S8 and N16 exist in deeper water than N11 and S3. Other sites such as sites $\mathrm{Z}$, DD, and LD were only occasionally sampled, often when an issue with water quality drew attention (Figure 6). 


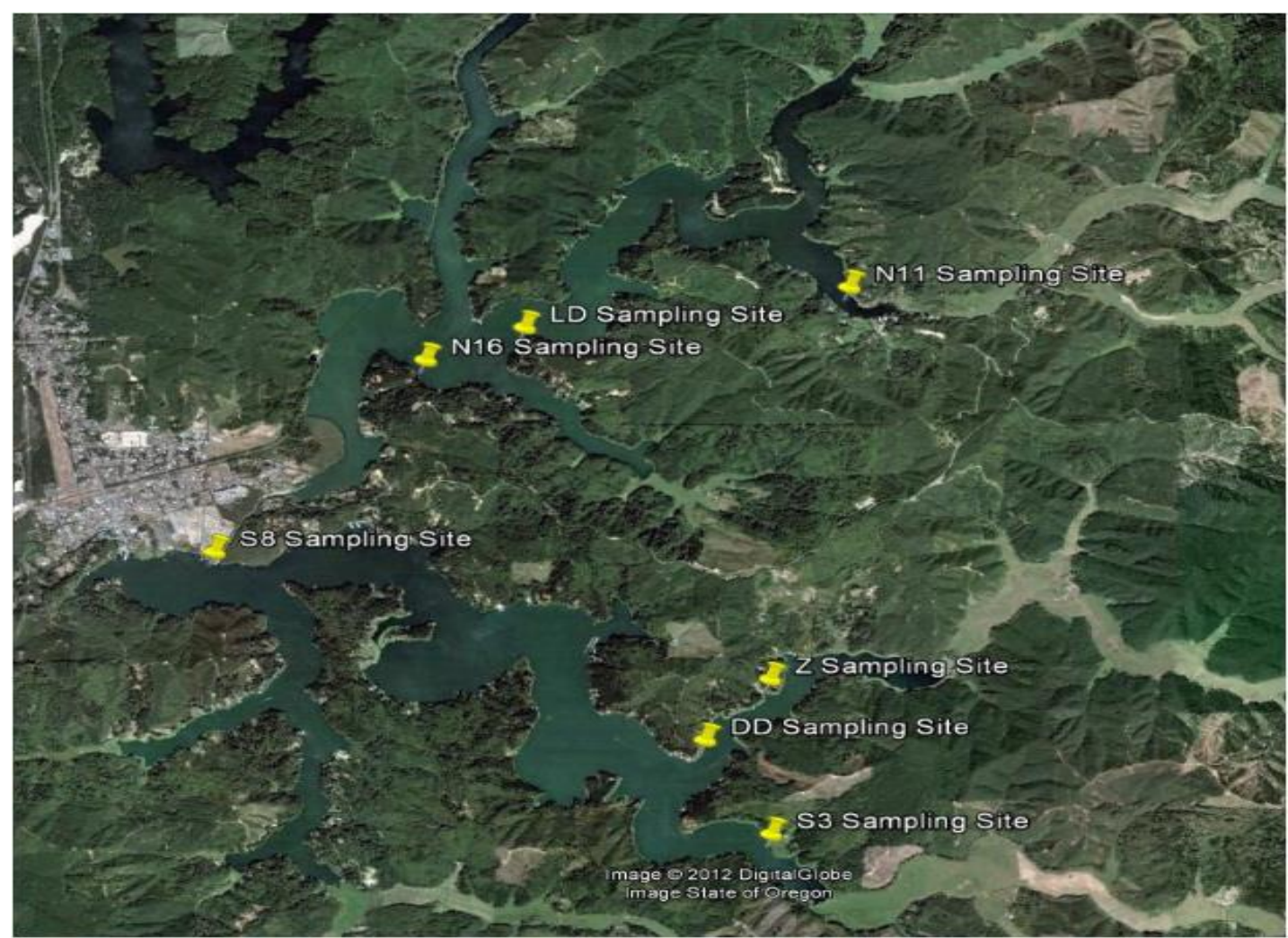

Figure 4 Sample Site Locations for North and South Tenmile Lake.

Image from Earth Explorer (USGS)

\subsection{Satellite Data Processing}

Satellite imagery is processed using MatLab ${ }^{\mathrm{TM}}$ software. MatLab stands for Matrix Laboratory, and is specifically designed to process large data arrays. A typical satellite scene has more than 8,000 rows and 7,000 columns. MatLab has many built in functions, and users are also able to write programs specifically targeting their needs.

The satellite and instrument chosen for this study is Landsat 5 Thematic Mapper. The satellite and instrument were chosen because of availability and cost of data, spatial resolution, and existing methods for the use of the instrument in water quality data determination.

The Landsat missions represent the longest continuous satellite record of the earth, beginning in 1972 with Landsat 1 and currently with the operation of Landsat 8 (Figure 5). The instruments on different Landsat satellites are calibrated in a manner that allows for use of the data between satellites. Aside from Thematic Mapper, Landsat 5 included a MultiSpectral Scanner, MSS. 


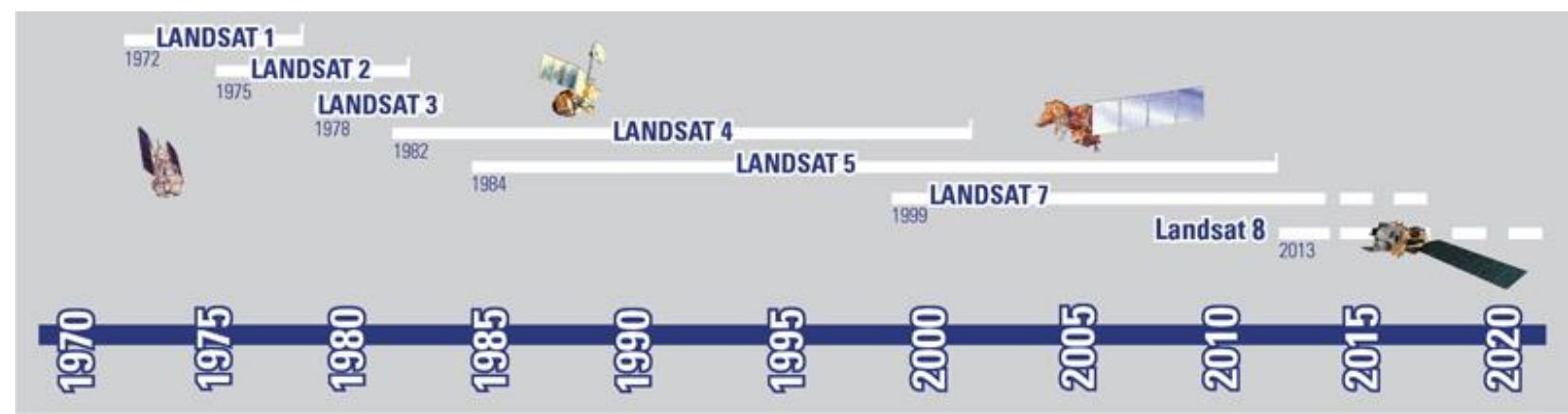

Figure 5 Timeline of Landsat Missions

Retrieved from http://www.USGS.gov

The Thematic Mapper used in this study has three bands in the visual spectrum, two bands in near infrared, one band in mid infrared, and one thermal infrared band for temperature determination (Table 1). The spatial resolution of each band is $30 \times 30$ meters, except for the thermal band, which is $120 \times 120$ meters (Table 1). Landsat instruments provide a 16 day temporal resolution. However, since clouds and aerosols affect many measured data, the effective temporal resolution of good data is less. Higher frequency data such as MODIS do not have a resolution adequate for our site.

Table 1 Thematic Mapper Bands

\begin{tabular}{|c|c|c|}
\hline Band & Wavelength $(\mathbf{n m})$ & Resolution - Pixel Size (m x m) \\
\hline 1 & $450-520$ & 30 \\
\hline 2 & $520-600$ & 30 \\
\hline 3 & $630-690$ & 30 \\
\hline 4 & $760-900$ & 30 \\
\hline 5 & $1550-1750$ & 120 \\
\hline 6 & $10400-12500$ & 30 \\
\hline 7 & $2080-2350$ & \\
\hline
\end{tabular}

Landsat 5 Thematic Mapper data was obtained online through the United States Geological Survey, USGS. Earth Explorer and GloVis (Global Visualization Viewer) are both direct links from USGS online, and both allow the user to view the image as a graphic (jpeg) before ordering the image. This feature allows the investigator to choose scenes with minimal cloud cover. An 
example scene appears in Figure 6. Lake water data exists at about two week increments through the summer, and Landsat 5 acquires imagery every 16 days. Originally, sample data was compared with satisfactory satellite images obtained within +/- 5 days of a measurement sample. Because the coast frequently had large amounts of cloud cover, only 27 appropriate satellite scenes were found +/- 5 days of the summertime sampling program between 2004 and 2010 . However, a more stringent criterion of $+/-1$ day proved necessary, probably due to variability in conditions, and resulted in only 4 appropriate scenes. The satellite imagery from the acceptable time difference between satellite overpass and ground sampling is converted to numerical values in order to investigate the relationship between them.

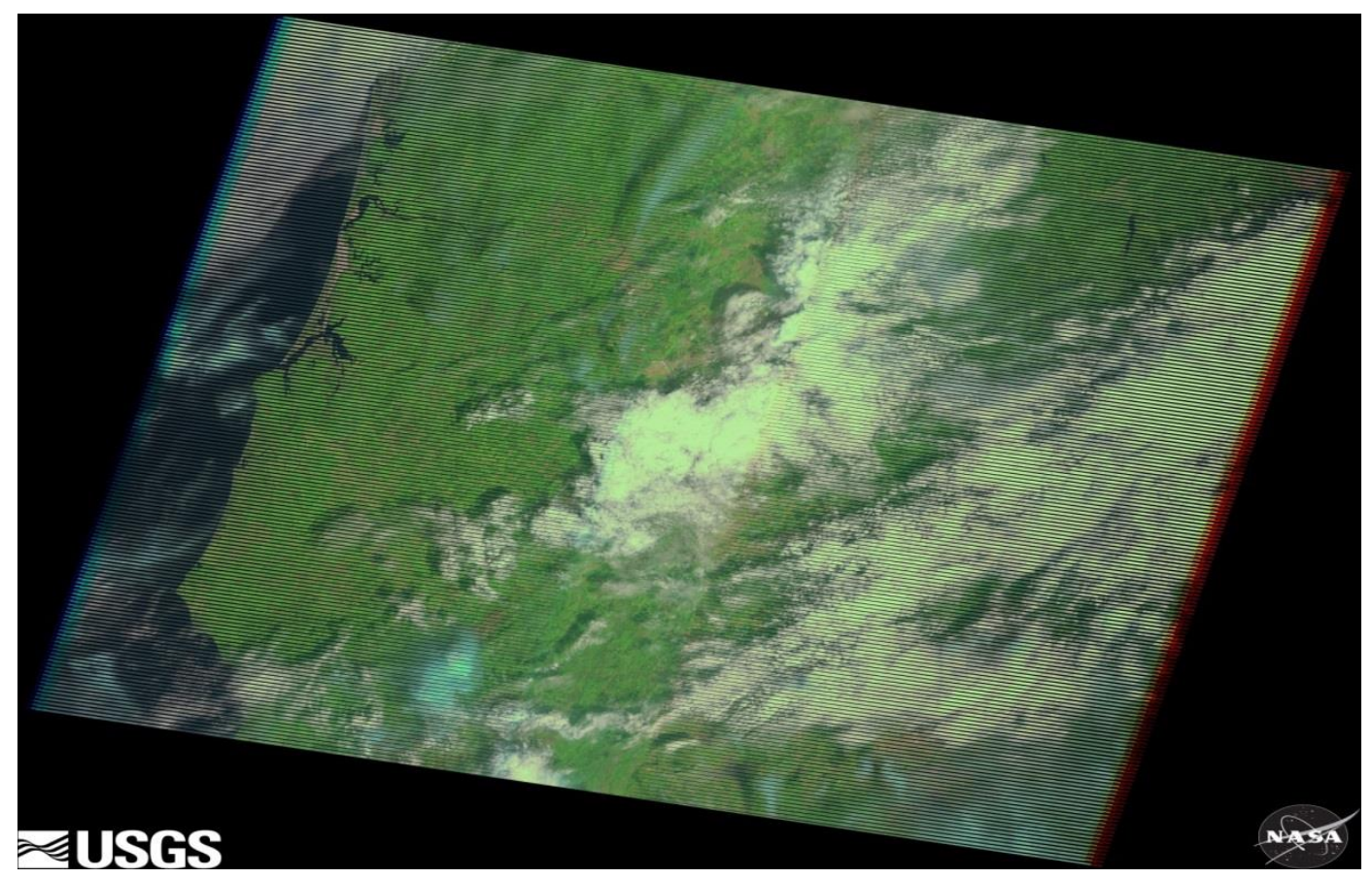

Figure 6 An example jpeg from Landsat 5 Path 47 Row 30 from July 11, 2007.

Once a scene is accepted by the user, it can be downloaded with or without processing. The scenes without processing are downloaded as a jpeg. Processed scenes are ordered and downloaded as a zipped file at a later date after processing to Level 1, which basically means the raw data is calibrated to a standard with common errors arising from problems with digitization, noise, and transmission corrected. The corrections to the common errors in the digital data are referred to as radiometric corrections. Multiple processed scenes are easiest to download with the "Bulk Data Application" available through USGS. Historically, processing to Level 1 
occurred by either the Level 1 Product Generation System (LPGS) or the National Land Archive Production System (NLAPS). Both radiometric and geometric differences existed between these Level 1 processing systems. However, since 2008, data from both methods is interchangeable. Different types of Level 1 processing occur, but are not necessarily publically available. Level 1 data all have systematic radiometric corrections. Level $1 \mathrm{G}$ "provides systematic radiometric and geometric accuracy" (NASA, 1999). Locations are up to $250 \mathrm{~m}$ incorrect. Level 1T has two sub-categories, precision and terrain corrected. The Level $1 \mathrm{~T}$ precision data utilizes elevation data whereas the terrain corrected category is corrected by means of a Digital Elevation Model (DEM). Level $1 \mathrm{~T}$ is also geometrically corrected with Ground Control Points (GCPs) where possible. Level $1 \mathrm{Gt}$ data also exists, but it is only in use for Antarctica data. The Level of processing for each scene is found in the metadata file (_MTL.txt). This data for this study is corrected with GCPs. An image of GCPs accompanies the scene data, and is found, if available, in the unzipped scene folder as a _GCP.txt file. Each unzipped scene folder also contains a GeoTIFF image of the scene for each band. These GeoTIFF images are in Gray Scale, and are read into MatLab as an unsigned 8-bit integer of Digital Numbers (DNs). The DNs are calibrated for any Level 1 processed data. The scale is from 0 to 255 , and the DN is related to the magnitude of the radiance for a given pixel in the image. The radiance is a quantitative measure of the amount of electromagnetic energy associated with a given pixel.

Pixel locations are derived from the scene corner locations given in the metadata. The corner locations for a scene are given in meters using the Universal Mercator Projection and the World Geodetic System (WGS) 84. The number of rows and columns of Digital Numbers obtained for a scene will match with the distances calculated from the corners of the scene based on the resolution of the pixel size, 30 meters a side for most bands of Thematic Mapper. The Digital Numbers represent the center of a pixel, so it is necessary to adjust the UTM projected X and Y location vectors generated in MatLab by half a pixel (15 meters). After reading the band data into MatLab and assigning vector locations, an array of Digital Numbers exists for each band for each pixel of the scene. A typical scene has about 7,200 rows and 8,100 columns of pixels. Bands 1 through 5 and Band 7 are utilized in this work. Band 6 of Thematic Mapper, however, was not used for this study because it is the thermal band. 
Most researchers used Digital Numbers directly, with or without an atmospheric correction most effective for water bodies, Dark Object Subtraction (DOS) (Hadjimitsis, 2004). The dark object is the pixel from an image that has the lowest value. The idea is that the lowest value exists due to attenuation by haze and aerosols. By subtracting the value of the darkest object from each pixel value, the attenuating effects of haze and aerosols are considered. In this study, the differences between the use of Digital Numbers with a form of Dark Object Subtraction, the use of Radiance, and the use of Radiance with Dark Object Subtraction were investigated. Vincent used a modified form of DOS by subtracting one from the darkest object (pixel). Because a value of zero is common for multiple pixels on cloud free days, Vincent subtracted one from the dark pixel. This allows for the use of ratios of radiance.

Conversion from Digital Numbers to "at sensor" spectral Radiance is covered in full detail in Chander, 2003. The general form of the equation is shown in Equation 1.

\section{Equation 1:}

where

$$
L_{\lambda}=\left(\frac{L M A X_{\lambda}-L M I N_{\lambda}}{Q_{C A L M A X}}\right) Q_{C A L}+L_{M I N}
$$

$L_{\lambda} \quad$ spectral radiance at the sensor's aperture in $\mathrm{W} /\left(\mathrm{m}^{2} * \mathrm{sr} * \mu \mathrm{m}\right)$

$Q_{C A L} \quad$ quantized calibrated pixel value in $\mathrm{DN}$

$Q_{C A L M A X} \quad$ maximum quantized calibrated pixel value $(\mathrm{DN}=255)$, corresponding to $L M A X_{\lambda}$

$\operatorname{LMIN}_{\lambda} \quad$ spectral radiance scaled to $\mathrm{Q}_{\mathrm{CALMIN}}$ in $\mathrm{W} /\left(\mathrm{m}^{2} * \mathrm{sr} * \mu \mathrm{m}\right)$

$L M A X_{\lambda} \quad$ spectral radiance scaled to $\mathrm{Q}_{\text {CALMAX }}$ in $\mathrm{W} /\left(\mathrm{m}^{2} * \mathrm{sr} * \mu \mathrm{m}\right)$

Defining two more terms simplifies equation 1.

$$
\begin{gathered}
G_{\text {rescale }} \equiv\left(\frac{L M A X_{\lambda}-\operatorname{LMIN}_{\lambda}}{Q_{\text {CALMAX }}}\right) \\
B_{\text {rescale }} \equiv \operatorname{LMIN}_{\lambda}
\end{gathered}
$$

Equation 2 is then a simplified Equation 1.

Equation 2:

$L_{\lambda}=G_{\text {rescale }} \times Q_{C A L}+B_{\text {rescale }}$

$\mathrm{G}_{\text {rescale }}$ and $\mathrm{Q}_{\mathrm{CAL}}$ are terms that are important in analysis of Thematic Mapper radiances because they allow for true values outside of the grayscale range of $0-255$, and for values less than 0 . 
Chander 2003, Chander 2007, and the metadata file accompanying each scene frequently give different rescaling values, based on calibration data, and this is the difference between the pre2008 Level 1 processing systems (NLAPS and LPGS).

Exoatmospheric radiance changes throughout the year, and depends on the earth-sun distance. For this reason, any study that occurs over time usually relies on reflectance. A pseudoinvariant object technique is often employed to adjust the radiance for multiple scenes over time. This study uses the varying earth-sun distance and sun zenith angle to adjust values for time stability. The equation for converting radiance to reflectance is shown in Equation 3 (Chander, 2003).

Equation 3:

where

$L_{\lambda} \quad$ spectral radiance at the sensor's aperature

$d \quad$ Earth-sun distance in astronomical units

$E_{X U N} \quad$ mean solar exoatmospheric irradiances

$Z \quad$ solar zenith angle in degrees

Spectral irradiance refers to the electromagnetic energy emanating from the sun. Irradiance is most often absorbed or reflected by an object: the reflected irradiance is then detected as radiance. Table 2 provides the Thematic Mapper exoatmospheric spectral irradiance by band, estimated with the CHKUR solar spectrum in the MODTRAN 4.0 software (Chander, 2003). MODTRAN is an atmospheric radiative transfer program. Data in Table 2 is for Landsat 5 only as other Landsat satellites may have different values. The thermal band, Band 6, calibration constants are provided separately.

Table 2 Exoatmospheric Spectral Irradiance, $\mathbf{E S U N}_{\lambda}$ in $\mathbf{W} /\left(\mathbf{m}^{2} * \mu \mathbf{m}\right)$

\begin{tabular}{|c|c|c|c|c|c|c|}
\hline Band & 1 & 2 & 3 & 4 & 5 & 7 \\
\hline$E_{S U N}$ & 1957 & 1826 & 1554 & 1036 & 215.0 & 80.67 \\
\hline
\end{tabular}

Chander, 2003

Table 3 provides the earth-sun distance used in equation 3 with the Day of Year abbreviated as DOY. This study used linear interpolation to obtain the exact distance for a given day to calculate reflectance and to calculate the normalized radiance. The normalized radiance is the 
radiance corrected for the sun angle and for a constant Earth-Sun distance of 1 astronomical unit, hence "Normalized".

Table 3 Earth-Sun Distance in Astronomical Units for Use in Equation 3.

\begin{tabular}{|c|c|c|c|c|c|}
\hline \multicolumn{5}{|c|}{ Earth-Sun Distance in Astronomical Units } \\
\hline DOY & Distance & DOY & Distance & DOY & Distance \\
\hline 1 & 0.9832 & 121 & 1.0076 & 242 & 1.0092 \\
\hline 15 & 0.9836 & 135 & 1.0109 & 258 & 1.0057 \\
\hline 32 & 0.9853 & 152 & 1.014 & 274 & 1.0011 \\
\hline 46 & 0.9878 & 166 & 1.0158 & 288 & 0.9972 \\
\hline 60 & 0.9909 & 182 & 1.0167 & 305 & 0.9925 \\
\hline 74 & 0.9945 & 196 & 1.0165 & 319 & 0.9892 \\
\hline 91 & 0.9993 & 213 & 1.0149 & 335 & 0.986 \\
\hline 106 & 1.0033 & 227 & 1.0128 & 349 & 0.9843 \\
\hline \multicolumn{7}{|c}{} & 365 & 0.9833 \\
\hline
\end{tabular}

Chander, 2003

Once the full band was read into MatLab as an array of Digital Numbers, the dark object was found and recorded, and a "rectangle" around the lake was assigned as UTM XY locations. This rectangle of Digital Numbers and the XY location vectors were then extracted from the full scene arrays for each band. Any unused band data was then deleted. After the smaller lake rectangle data array was created, an outline of the lake, expressed as many XY points, was used. The lake outline was obtained through the National Hydrology Database (NHD) from a link to USGS. The shapefile is read into MatLab along with supporting files. The outline for North Tenmile Lake had around 1700 latitude - longitude pairs, and South Tenmile Lake outline had around 2200 latitude - longitude pairs. The values were projected to XY in UTM before using in MatLab.

Once the reflectance and the normalized radiance are calculated, the satellite data was compared with the data obtained from testing on the lake. To calibrate the Thematic Mapper data to in-situ ground measurements, the four most common sample site locations, S3, S8, N11, and N16, were read into MatLab and projected to UTM. The find function in MatLab was then used to identify which pixel of the satellite array corresponds to the sample site. A 3 x 3 grid was then set up with the sample site pixel in the center. Pseudocolor, or MatLab "pcolor", plots of this 3 x 3 grid were used to spot check data for outliers or other problems. For example, the original sample 
site location for $\mathrm{S} 3$ yielded Not a Number $(\mathrm{NaN})$ for the lower right pixel. NaN values were assigned to pixels representing land. The original S3 sample site location was then moved North and West to insure it represented the radiance from water close to the sample site. Once spot checked, a representative Digital Number was obtained from the median of the average of each row in the $3 \times 3$ grid.

\subsection{Vincent Algorithm for Phycocyanin}

After the manipulations of water and satellite data were complete, testing the functionality of an algorithm for monitoring Phycocyanin (Vincent, 2004) was a simple extension of the existing analysis. Phycocyanin (PC) is a light harvesting accessory pigment to Chlorophyll, and is specific mostly to cyanobacteria. In-situ measurements of the Phycocyanin concentration in a water body are frequently used as a proxy for the quantity of blue-green algae. A common method used for quantifying PC concentrations utilizes a hand held spectrophotometer with either narrow band resolution where needed or with filters. Phycocyanin has an absorption peak at $630 \mathrm{~nm}$ and a fluorescence peak at $660 \mathrm{~nm}$, while Chlorophyll a has an absorption peak at 430 $\mathrm{nm}$ and a fluorescence peak at $680 \mathrm{~nm}$. The process is referred to as IVPF/IVCF, or in-vivo Phycocyanin fluorescence / in-vivo Chlorophyll fluorescence. The measurements are commonly taken in the field.

Analytical models exist for the quantification of Phycocyanin for satellites with a narrow enough wavelength resolution in the appropriate wavelength ranges. Essentially, remote sensing with satellites is employing the same methods utilized by IVPF/IVCF. Hyperspectral instruments work well for this application. MERIS is also capable of determining Phycocyanin concentrations in the ppb range (Simis, 2005).

Landsat's instruments Thematic Mapper and Enhanced Thematic Mapper +, $(\mathrm{ETM}+)$, possess three broad absorption bands in visible wavelength ranges. Additionally, each has two bands in the NIR, one band in the MIR, and one thermal band. Landsat 7's ETM+ has an additional panchromatic band. Vincent, et al., reports to have developed an algorithm for the in-vivo 
quantification of Phycocyanin concentration with both Landsat 5 Thematic Mapper and Landsat 7's ETM+ (Vincent, 2004).

Vincent used DNs that subtract the Dark Object minus one. The Dark Object minus one is necessary to avoid dividing by zero as many cloud free days have a DO value of zero. The study site is Lake Erie near Maumee Bay, Ohio. Two dates are used in the study; July 1, 2000 for Landsat 7 and September 27, 2000 for Landsat 5. A dominant and long lasting Microcystis bloom was present during both sample dates. Thirty samples and twenty samples were collected for the Landsat 7 overpass and Landsat 5 overpass. The spacing of the sample grid was approximately $2 \mathrm{~km}$. Vincent utilized an image processing software package, ERMAPPER, and a statistical processing software program, Minitab, to conduct his study.

The outcome of the study was the best statistical fit to the sum of single bands and to band ratios. All of the equations are linear, and appear in Table 4.

Table 4 Vincent Algorithms for Phycocyanin ( $\mu \mathrm{g} /$ liter).

\begin{tabular}{|l|l|l|l|l|}
\hline & Landsat 5 TM & Adj. R2 & Landsat 7 ETM+ & Adj. R2 \\
\hline Single Band & Undetermined & & PC=b-B1+B3-B5+B7 & 0.738 \\
\hline Band Ratio & PC=b+R31-R42-R53-R75 & 0.632 & PC=b-R31+R41-R43-R53+R73-R74 & 0.776 \\
\hline
\end{tabular}




\subsection{RESULTS AND DISCUSSION}

The correlation of satellite data to turbidity for different data types help explain why DNs are so frequently used given the difficulty in transforming them to radiance or reflectance. The fit of TM data to Turbidity, biovolume, Chlorophyll a, and Phycocyanin is investigated in this section.

\subsection{Calibration}

Secchi depth was measured during every sampling expedition between 2006 and 2010, but turbidity was only obtained sporadically during this period. Figure 7 shows that Secchi depth and turbidity are correlated, based on data collected within $+/-1$ day of a satellite overpass (2 total events). Secchi depth versus Turbidity is correlated to an $\mathrm{R}^{2}$ of 0.58 , using the non-linear regression fit shown in Figure 7.

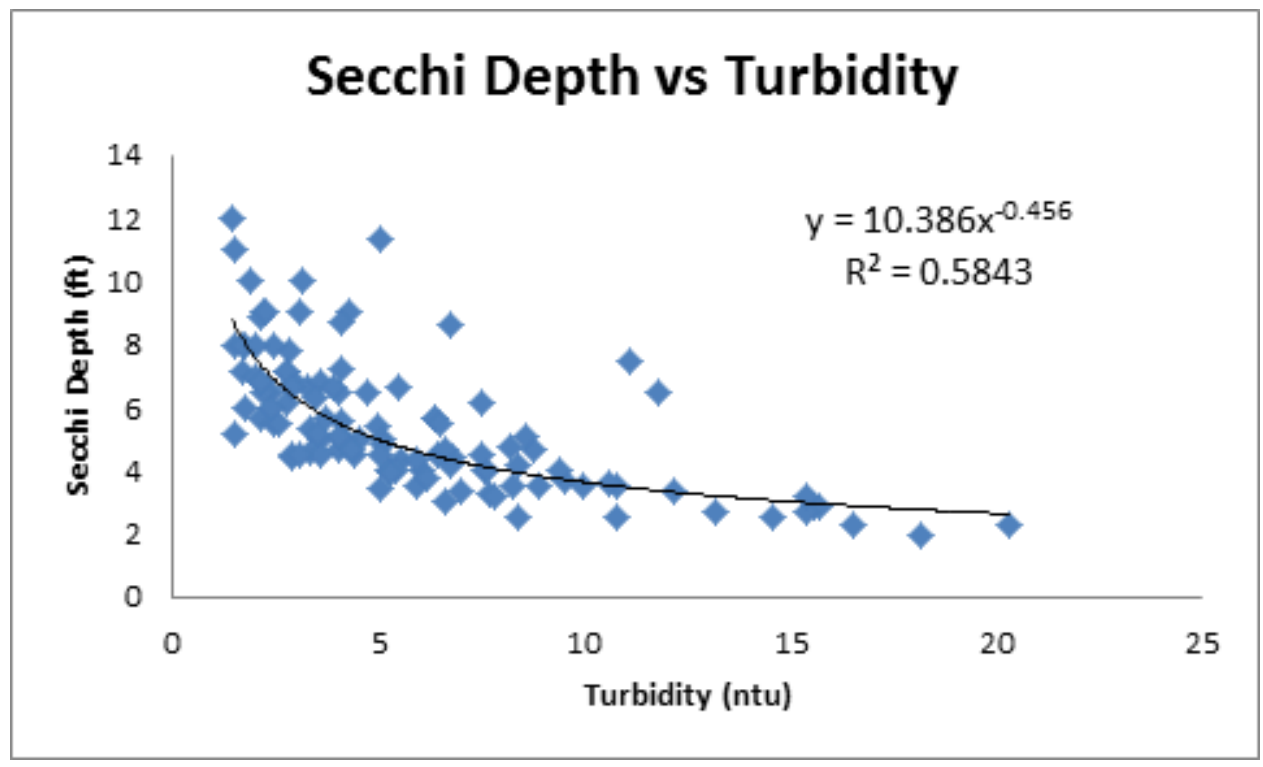

Figure 7 Secchi Depth versus Turbidity.

In order to simplify the data set and to make the predictions more robust, similar values for the Secchi Depth were placed into bins and averaged along with the corresponding Turbidities. This bin averaged curve appears in Figure 8. 


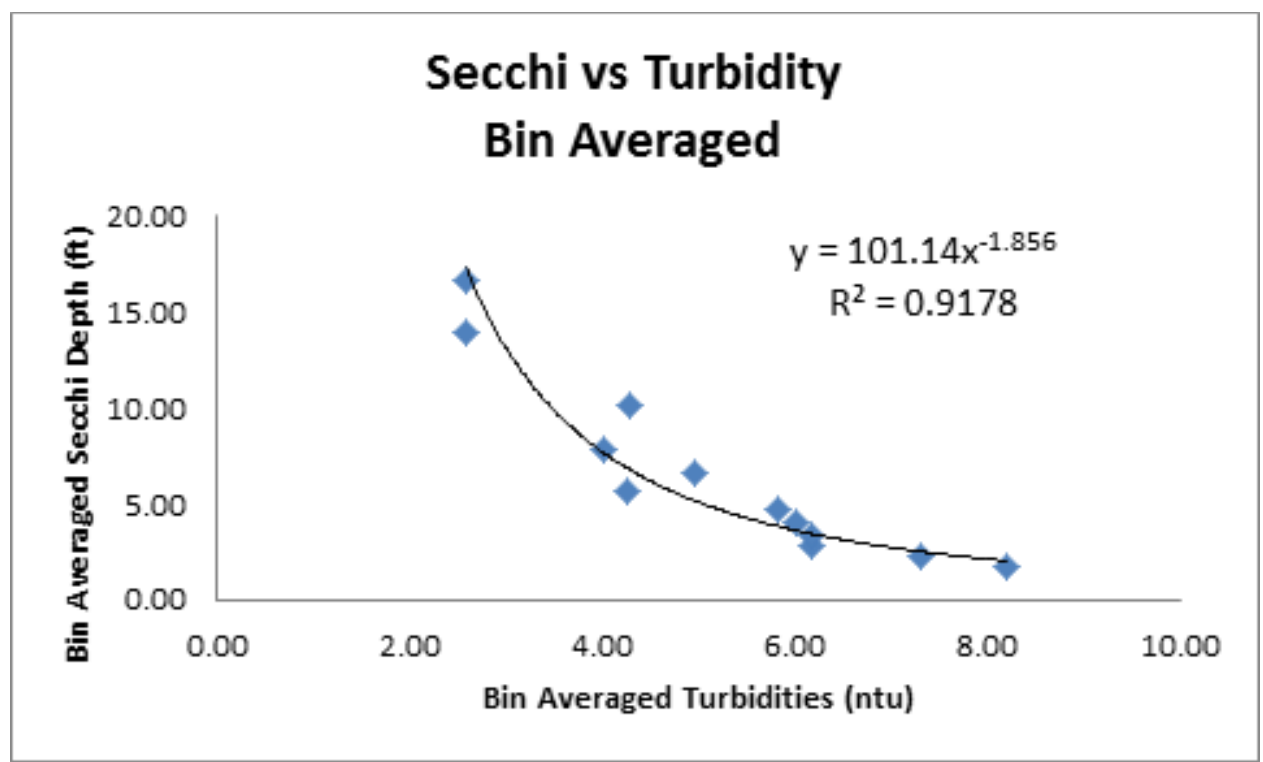

Figure 8 Bin Averaged Secchi Depth vs Turbidity.

The bin averaged Secchi depth versus turbidity equation was used to generate missing turbidity values from existing Secchi depth. The results were grouped into two categories; one with turbidity values from only Secchi depth, referred to as Equation Turbidity, and one with measured turbidity values where possible, referred to as Combined Turbidity. Normalized DNs were used to investigate turbidity.

Common methods for fitting turbidity data to Thematic Mapper data include regressing individual bands and band ratios against available in-situ data (Kutser, 2004, Harrington, 1992, Ritchie, 1990). For our data, the only band or band ratio that yielded any promising results was Band 1, the blue band, when regressed against the combined (Secchi depth and Turbidity) data set. Nonetheless, the scatter in the data suggests that other factors are important and were not measured/detected/corrected for in the satellite data and/or the in-situ measurements. The time lag between measurements and satellite data may be important as well.

A plot of Combined Turbidity versus TM Band 1 Normalized DN (DNN) appears in Figure 9. 


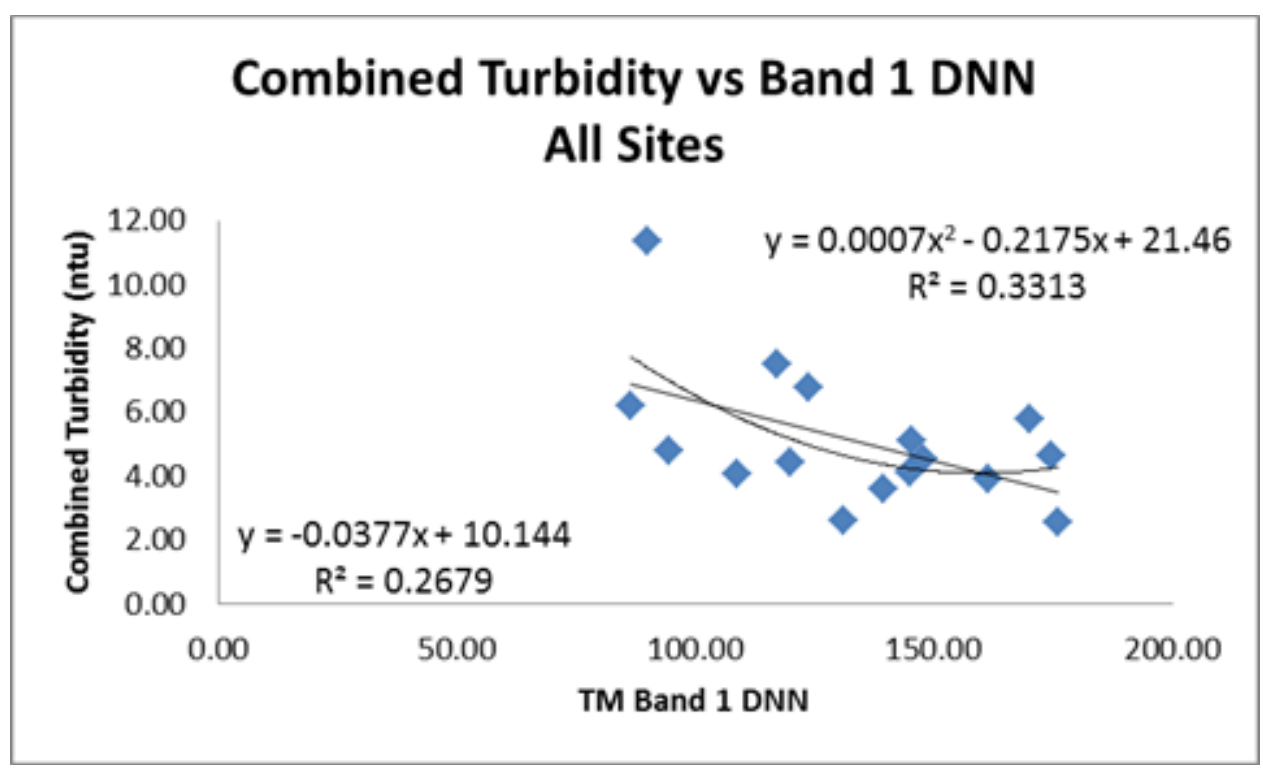

Figure 9 Plot of Combined Turbidity versus TM Band 1 DNN for all data points for all sites.

Review of source data for the plot in Figure 9 revealed that the DNNs for Site N11 was much higher than all the other sites DNNs, especially in the near-infrared and mid-infrared bands. The source data for the plot in Figure 9 appears in Table 5.

Table 5 Source Data for the Plot in Figure 11.

Note Site N11's Values Highlighted.

\begin{tabular}{|c|c|c|c|c|c|c|}
\hline DNN & Band 1 & Band 2 & Band 3 & Band 4 & Band 5 & Band 7 \\
\hline S8DNN8210 & 117.21 & 48.84 & 38.42 & 29.30 & 23.44 & 14.98 \\
S8DNN7191 & 174.76 & 71.52 & 61.20 & 53.83 & 36.13 & 24.33 \\
S8DNN6204 & 139.40 & 55.21 & 45.55 & 33.12 & 26.91 & 17.25 \\
S8DNN10256 & 145.32 & 65.08 & 65.57 & 84.65 & 102.26 & 57.25 \\
S3DNN8210 & 123.73 & 54.05 & 44.93 & 42.98 & 37.12 & 22.14 \\
S3DNN7191 & 176.23 & 72.26 & 67.10 & 70.79 & 58.25 & 33.92 \\
S3DNN6204 & 147.68 & 62.80 & 55.21 & 54.52 & 40.71 & 23.46 \\
S3DNN10256 & 90.03 & 38.65 & 29.36 & 30.34 & 20.06 & 10.76 \\
N16DNN8210 & 108.75 & 44.93 & 36.47 & 58.61 & 47.54 & 21.49 \\
N16DNN7191 & 161.48 & 67.10 & 54.57 & 87.75 & 58.25 & 25.81 \\
N16DNN6204 & 131.12 & 51.76 & 40.02 & 61.42 & 49.00 & 23.46 \\
N16DNN10256 & 86.61 & 34.25 & 27.40 & 58.72 & 36.70 & 14.19 \\
N11DNN8210 & 119.82 & 56.00 & 48.19 & 196.66 & 134.80 & 46.89 \\
N11DNN7191 & 170.33 & 75.95 & 66.36 & 233.75 & 165.17 & 59.73 \\
N11DNN6204 & 144.92 & 64.87 & 55.21 & 206.33 & 149.75 & 55.90 \\
N11DNN10256 & 94.43 & 41.10 & 34.74 & 110.58 & 79.27 & 28.38 \\
\hline
\end{tabular}


Figure 10 is a plot of Combined Turbidity versus TM Band 1 DNNs excluding Site N11. The RSquared value is increased by $41 \%$. A review of larger data sets, the three and five day, revealed Site N11's data was all considerably higher than the other three sites.

N11's sample site location was confirmed before observing calibrated DNs in the surrounding area all possessed relatively high values. A discussion with TLBP about the sample sites revealed that N11 is a shallow location of 6 feet depth in the summer, but 16 feet in the winter due to greater precipitation during that time of the year. TLBP reports that there are "LOTS of aquatic weeds in that area. I have a hard time sampling because of the weed growth" (Richard Litts of TLBP). The site frequently yields "weird $\mathrm{pH}$ and DO readings". He also believes the septic systems in the area are "not up to par". A marina is located nearby, so there is heavy boat traffic. The boat traffic causes heavy wakes because the channel is narrow. Nearby Big Creek is a freshwater inlet with variable flow near the sample site, but in the winter it is high flow bringing in lots of sediment. A narrow channel indicates potential difficulty in measuring the correct pixel, and a variable amount of freshwater flux result in a more dynamic site. This especially becomes an issue when satellite overpass is not in close proximity to water sampling.

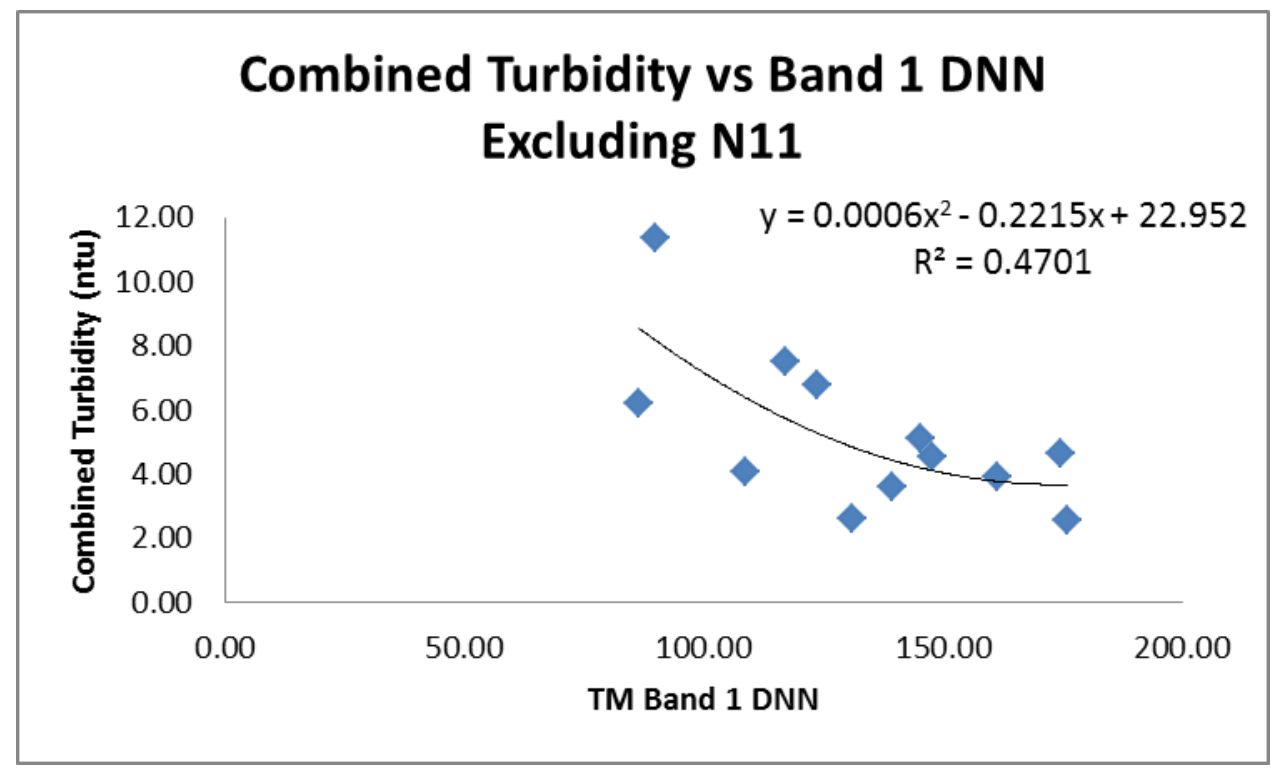

Figure $10 \quad$ Plot of Combined Turbidity versus TM Band 1 DNN's without Site N11 data.

Plots for bin averaged turbidity versus TM Band 1 DNN for all sites and for N11 excluded appear in Figures 11 and 12, respectively. Although the linear fit for the data that excludes Site 
$\mathrm{N} 11$ has a better fit $\left(\mathrm{R}^{2}=0.83\right.$ vs. $\left.\mathrm{R}^{2}=0.75\right)$, a quadratic fit yields a larger $\mathrm{R}^{2}$ when $\mathrm{N} 11$ is included $\left(\mathrm{R}^{2}=0.87\right.$ vs. $\left.\mathrm{R}^{2}=0.98\right)$. More data is needed to distinguish the correct model to use; though goodness of fit is better for the polynomial model, it has one fewer degree of statistical freedom. Moreover, the minimum resolution of both the satellite and in-situ data are unknown, though there is some suggestion that the satellite cannot resolve turbidity below 2-4 NTU. The linear models for Turbidity with and without Site N11 are used to estimate values elsewhere on the lake.

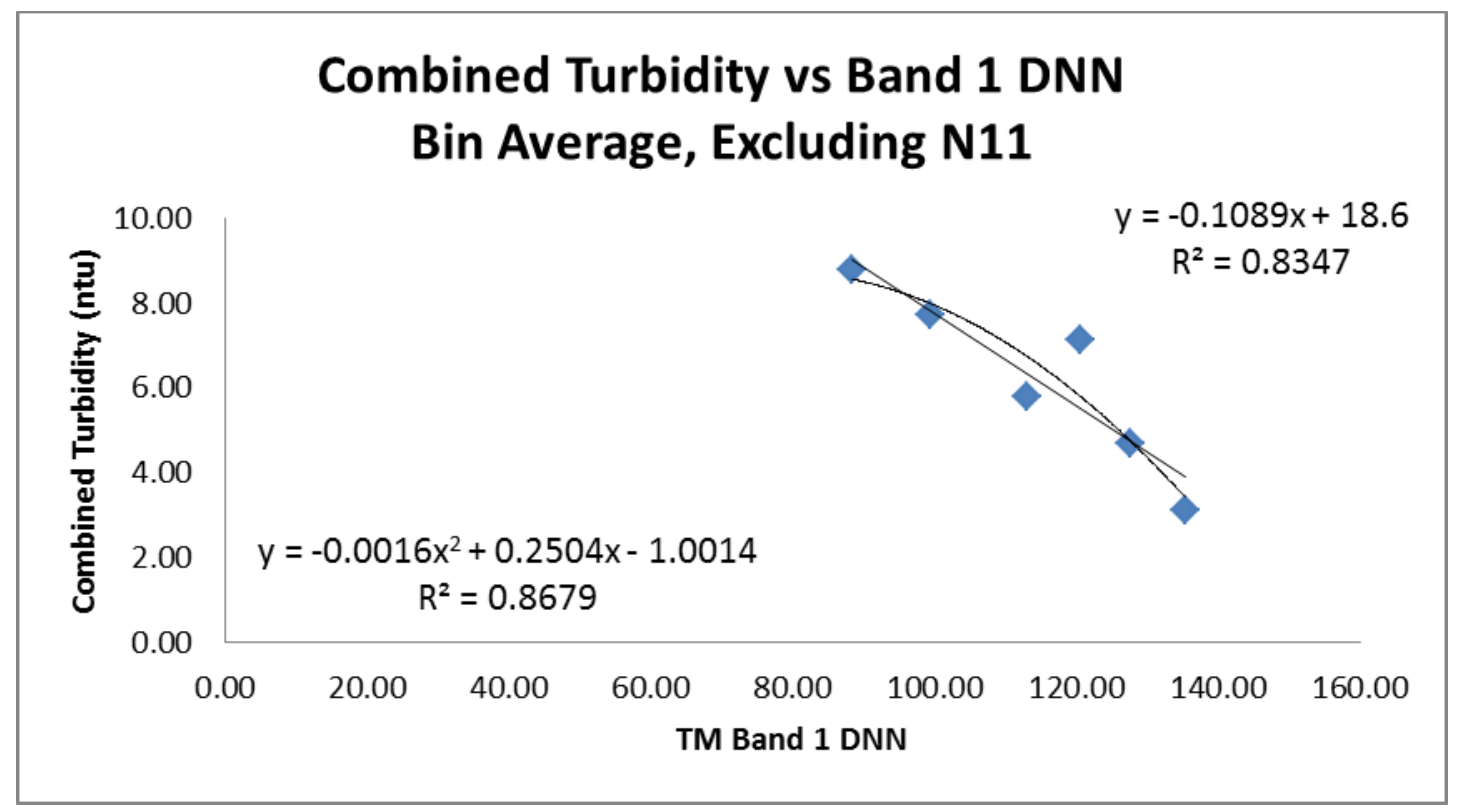

Figure 11 Bin Averaged - Combined Turbidity versus TM Band 1 DNN without N11. 


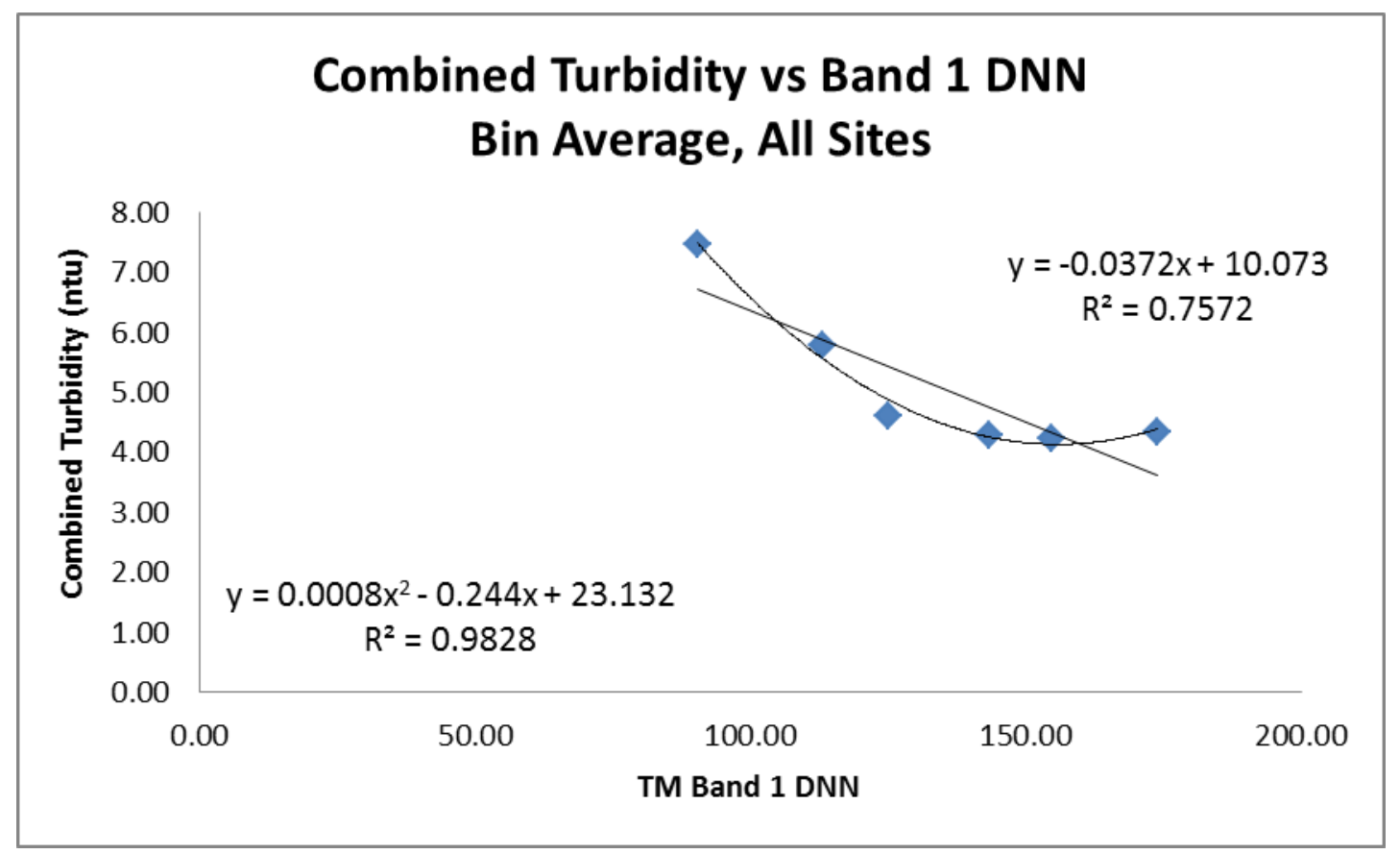

Figure 12 Bin Averaged - Combined Turbidity versus TM Band 1 DNN for all sites.

The curve obtained from exclusion of Site N11 has a greater slope, and therefore a greater range in calculated NTU. This is useful when utilizing the satellite to see turbidity gradients on the lake.

\subsection{Spatial patterns of turbidity}

The channels through the lake taken from freshwater inlets are more easily seen in the pseudocolor plots from the linear equation derived from Turbidity versus Band 1, excluding N11. Johnson Creek empties into Templeton Arm near station S3 on southeast portion of South Tenmile Lake in Figure 13. This inlet water can be tracked toward Tenmile Creek, appearing on the most western portion of South Tenmile Lake, by the light to dark blue appearance.

A second pseudocolor plot for August 18, 2004 appears in Figure 14. The spatial differences are most notable near the town of Lakeside, which appears just west of the channel on South Tenmile Lake. The difference is most likely explained by the amount of precipitation in the month of June compared to August. August is much drier and creek inflow is smaller, resulting in larger residence times in the lake. Sample site S8 for August 18, 2004 has a BGBV and TBV about 5 times greater than S8 for June 15, 2004, so it seems the higher turbidity seen is directly a result of the high algae population in the area. 


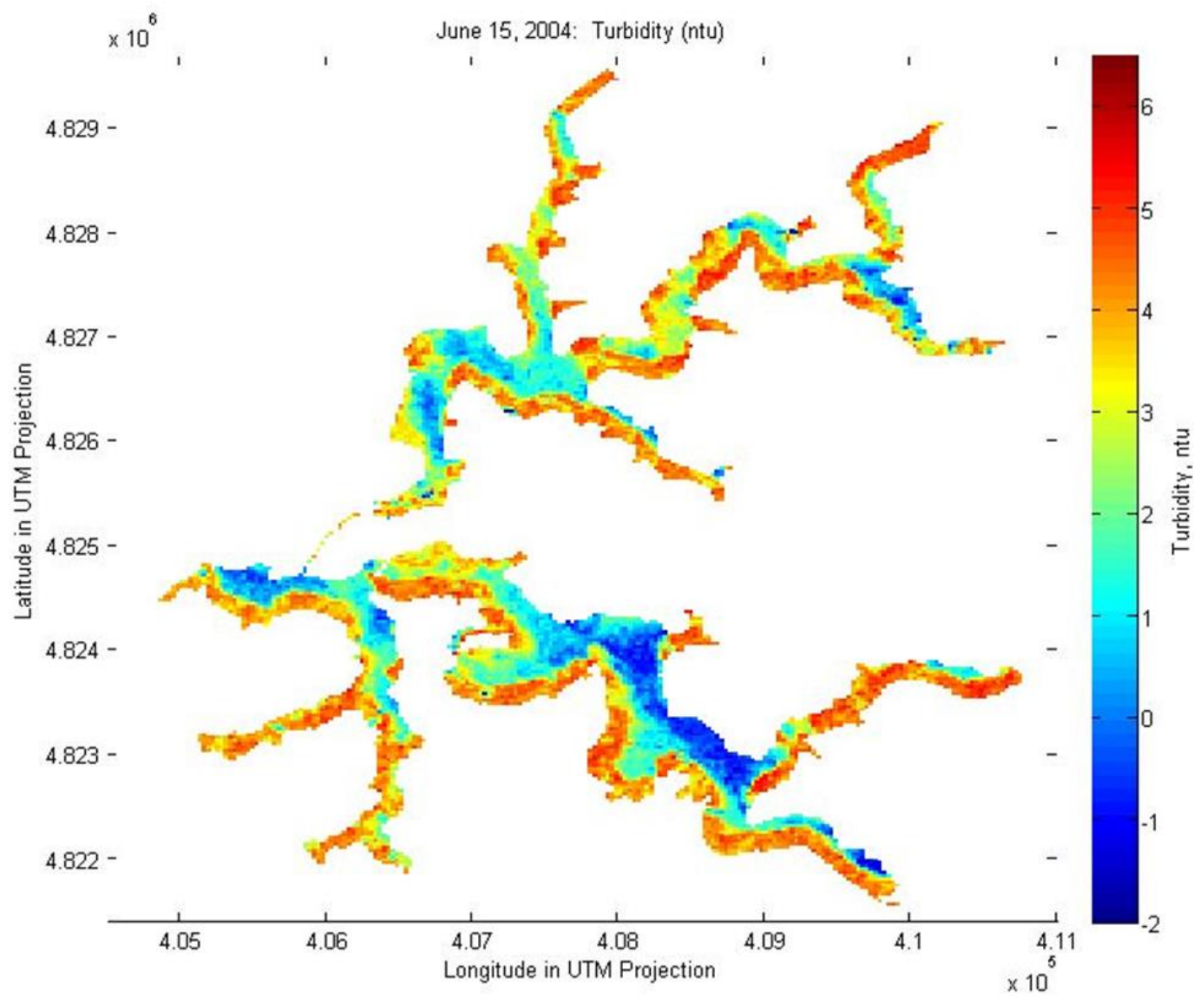

Figure 13 MatLab pcolor plot of Turbidity on Tenmile Lake for June 15, 2004 using the curve from Turbidity versus Band 1 with exclusion of Site N11. 


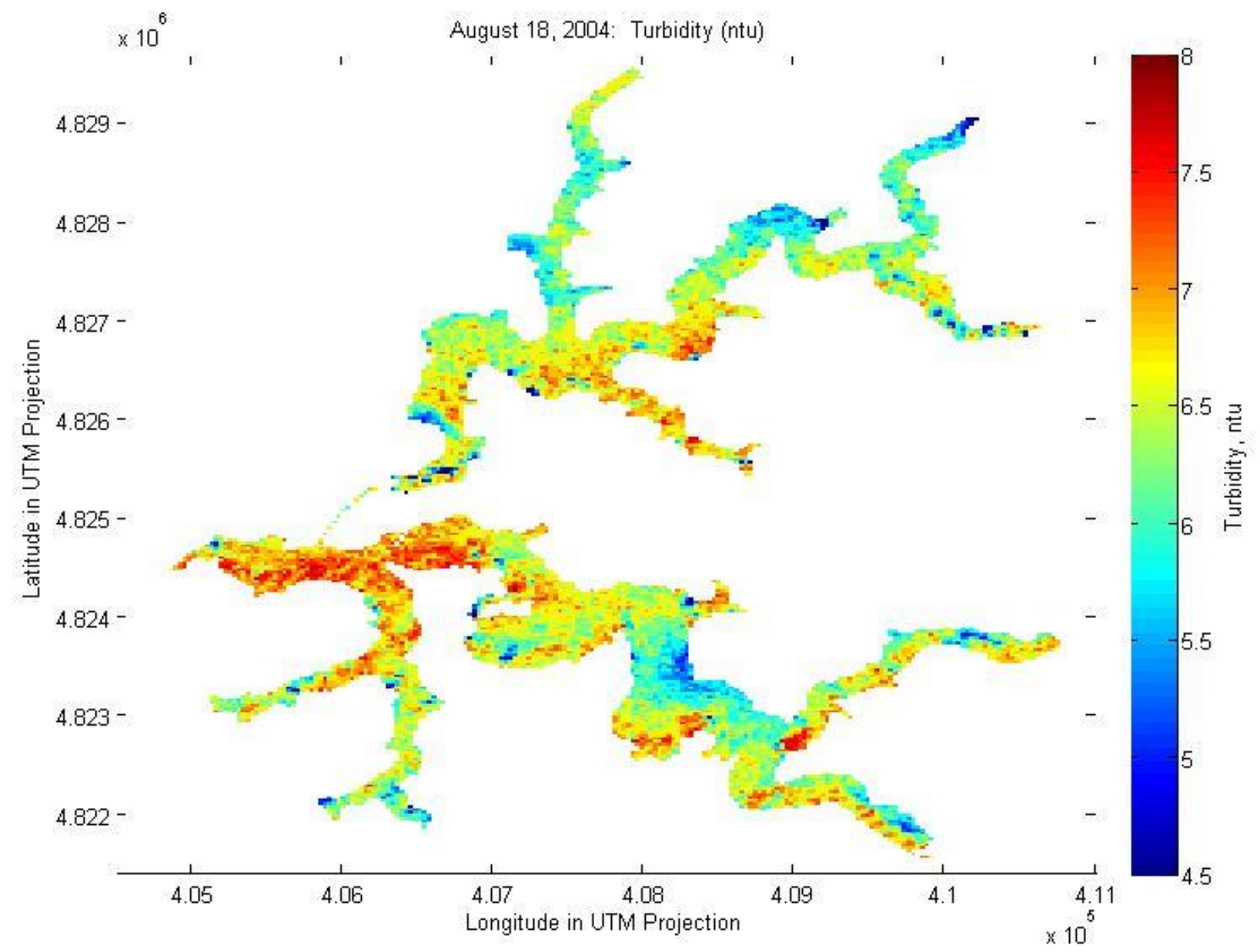

Figure 14 MatLab pcolor plot of Turbidity on Tenmile Lake for August 18, 2004. Based on linear Turbidity versus Band 1 curve without Site N11.

A plot of Combined Turbidity versus TM Band 1 DNN for individual sample sites appears in Figure 15. The slope for N11 is positive with a slope of 0.011 . The slopes for the other three sites have negative slopes of at least -0.042. All four sample sites have different lines. This is an indication of the difficulties in remote sensing freshwater quality parameters, especially for shallow freshwater lakes that are high in nutrients and Carbon Dissolved Organic Matter. This set of conditions, i.e. shallow, eutrophic, freshwater lake with high CDOM, represents the greatest challenge in satellite remote sensing (Kutser, 2009, Mayo, 1995, Ostlund, 2001, Ritchie, 1990, Sudheer, 2006, Tyler, 2006). Sites S8 and N16, while on different lakes, have the most similar slope and intercept. These two sites have the deepest water and the greatest flux of fresh water. The deeper water results in weeds or benthic zone sediment being less interference. 


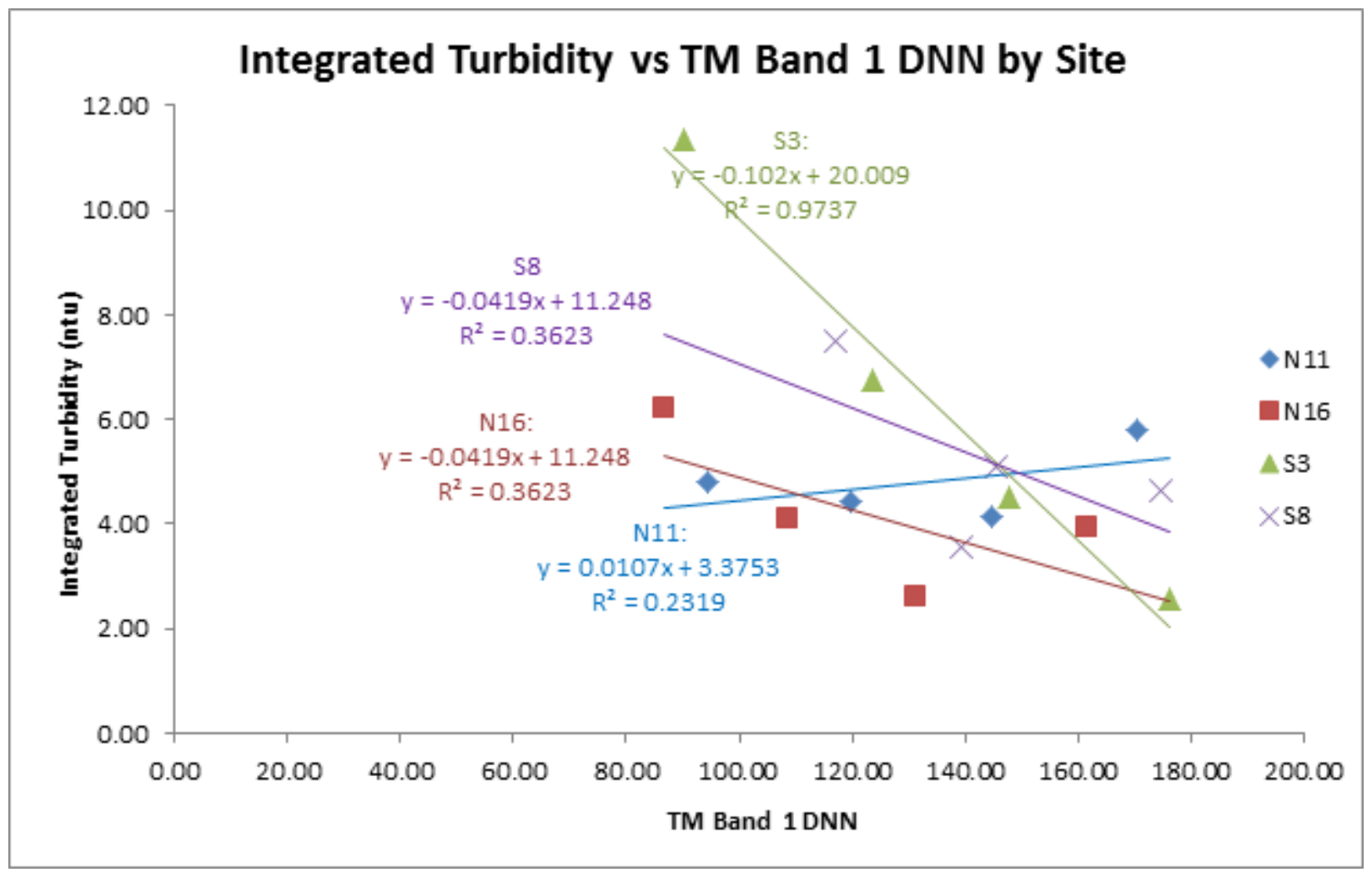

Figure 15 Combined Turbidity vs TM Band 1 DNN by Site.

The patterns of turbidity observed in our lake can be explained by Turner (2010) from the Oregon Department of Environmental Quality. This study proposed that eutrophic lakes were either sediment dominated or algae dominated, resulting in a different functional relationship between satellite data and in-situ turbidity measurements. In sediment dominated lakes, TM Band 3 or a ratio of Band 3 and Band 4 are best used to monitor turbidity (Harrington, 1992, Ritchie, 1990). In algae dominated lakes, turbidity is related to algal biovolume and Chlorophyll a concentration. Some methods for monitoring biovolume or Chlorophyll a involve the use of Band 1 or a ratio of Band 1 and Band 2 reflectance (Kutser, 2004, Mayo, 2009, Ritchie, 1990). Chlorophyll a reflects green (Band 2) and absorbs blue (Band 1). Using a ratio of Band 2 to Band 1 provides for a greater data resolution by removing correlated portions of the two bands.

Turner (2010) categorized many Oregon lakes according to trophic status based on TM band ratios. The status, or satellite color, of many Oregon lakes is shown in Figure 16. (Band 2 / Band 3) is on the ordinate, and (Band 2 / Band 1) is on the abscissa: The values for these band ratios yield the amount of green character to red and to blue, respectively. A healthy, ultra- 
oligotrophic lake has an overwhelmingly blue signal while an unhealthy, sediment dominated or algal dominated lake, has either a high red or high green signal, respectively.

Turner used a different method to atmospherically correct and to normalize his DNs. For Tenmile Lakes, Oregon, the DNN value obtained in this study for (B2/B1) is 0.45 . (B2/B3) has a value of 1.0. For normalized radiance with DOS, the values are 0.83 and 1.45, respectively. Averaged together the values become 0.64 and 1.24. In any case, Tenmile Lakes is classified as red and green, meaning it has a high level of sediment and algal growth with either high or ultrahigh levels of nutrient content.

These observations may explain the observed behavior in Site N11. Turbidity and algal biovolume are positively correlated, so the blue absorbance of Site N11 due to plant life close to or on the surface is helping compensate for decreased blue absorbance in sediment dominated regions or in shallow water.

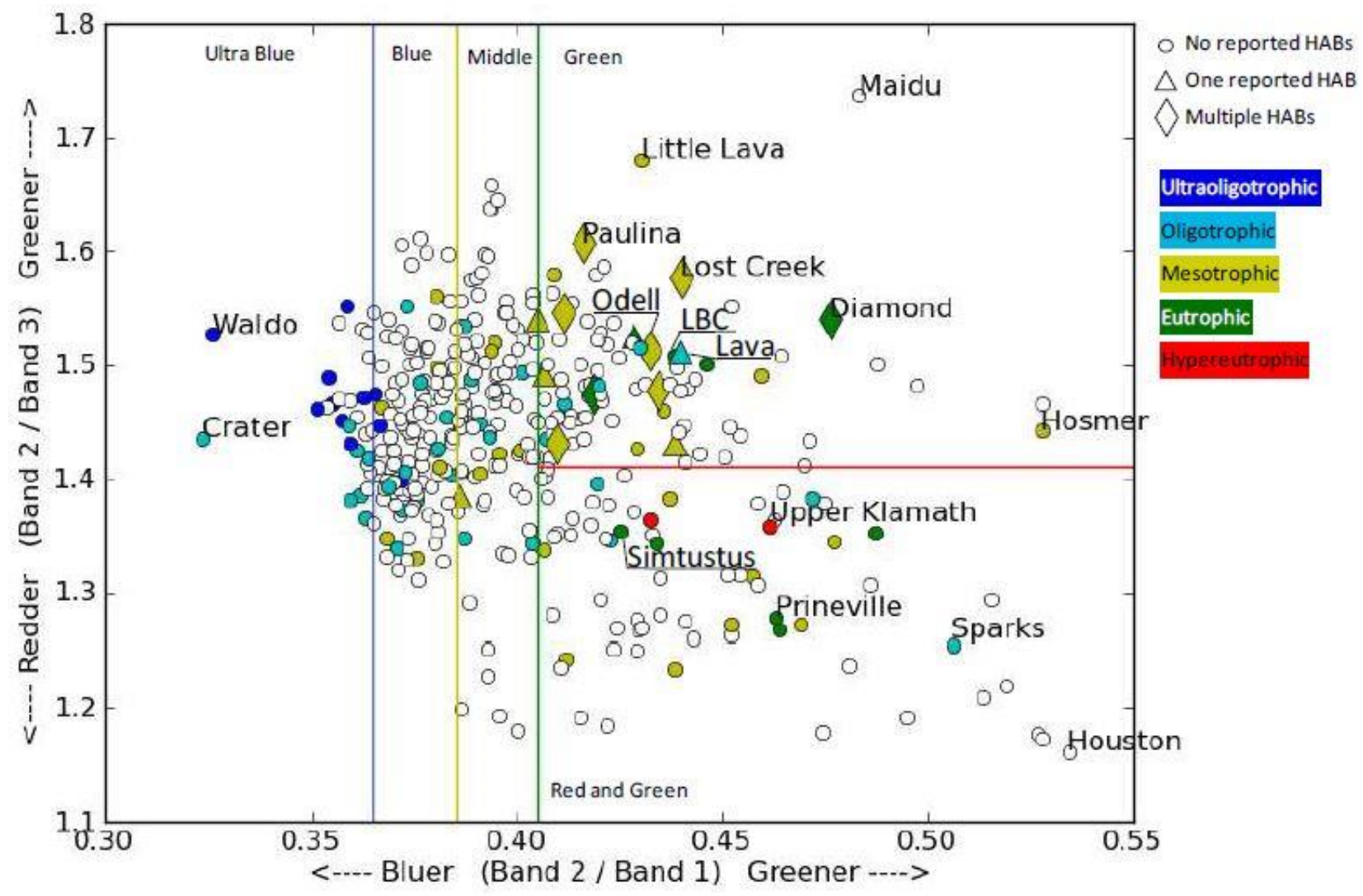

Figure 16 Plot for a Color Classification Scheme for Lakes.

Values obtained from different data types, DNN and Normalized DOS radiance, range from 0.45 to 0.83 for $\mathrm{B} 2 / \mathrm{B} 1$ and 1.03 to 1.45 for $\mathrm{B} 2 / \mathrm{B3}$. 


\subsection{Biovolume - Calibration and spatial patterns}

Plots for the $\log _{10}$ of both Total BioVolume (TBV) and Blue-Green BioVolume (BGBV) for Bands 1 and 2 appear in Figure 17 through Figure 20. Satellite imagery $+/-3$ days of the sampling date was used. In order to determine an algorithm that calculates a predicted biovolume based on satellite signal, biovolume was selected as the dependent variable and satellite signal as the independent variable. This method is common in temperature monitoring where the satellite signal or ratios of signals is used as in input for temperature output (Hulley, 2011).

All of the curves indicate that a polynomial best fit with Band 1 being better than Band 2 for both TBV and BGBV. These plots indicate that the quantification of biovolume with Landsat 5 Thematic Mapper is convoluted if not impossible, at least in algal dominated lakes. Polynomial curves are presented for three reasons. First, the lack of data at lower biovolumes results in clustered data that has no predictive use. Second, a polynomial fit better illustrates the peak and subsequent decrease in biovolume with increasing satellite signal which suggests that there are dynamics of the lake that are currently unknown. Finally, Sudheer (2006), states that too often satellite remotely sensed data is forced into a linear fit when the true correct fit is anything but linear. 


\section{Log TBV vs TM Band 1 Reflectance \\ All Sites. Bin Average.}

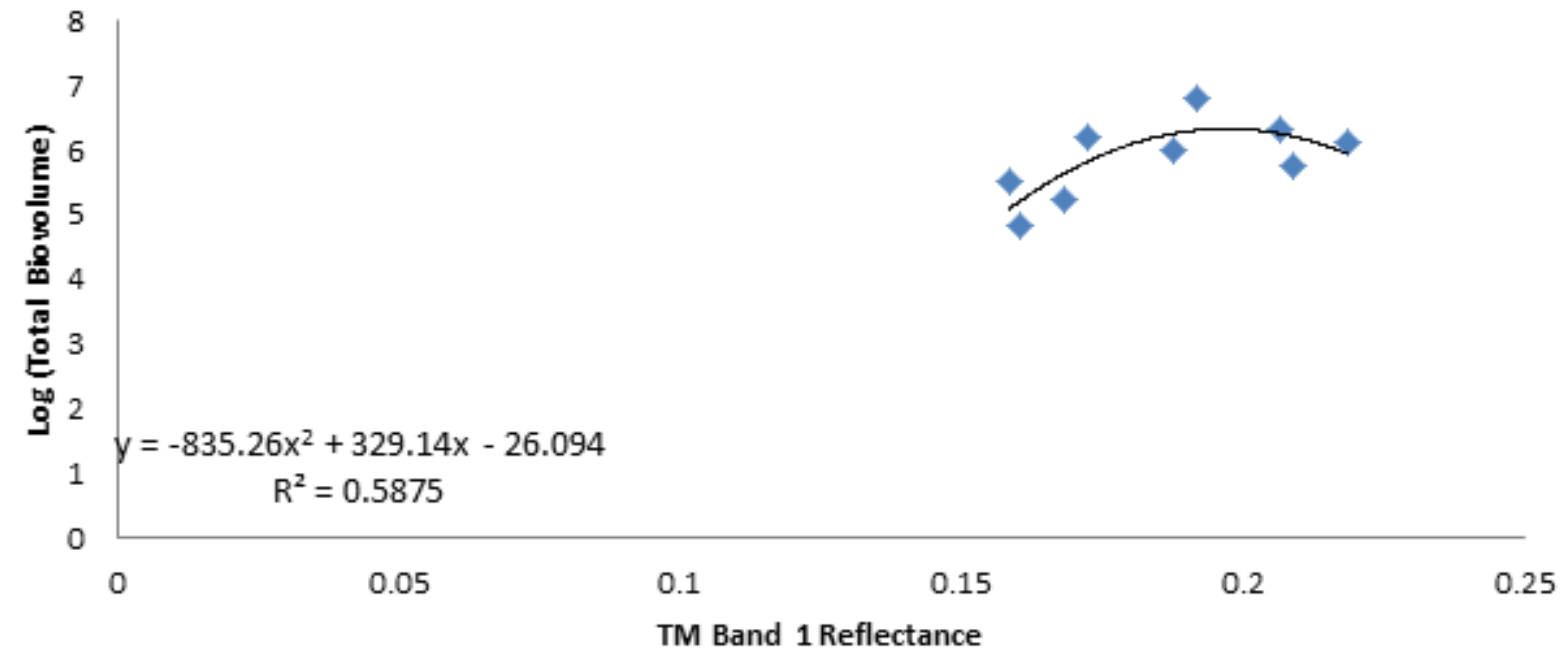

Figure 17 Binned Average for $\log _{10}(\mathrm{TBV})$ vs TM Band 1 Reflectance for All Sites.

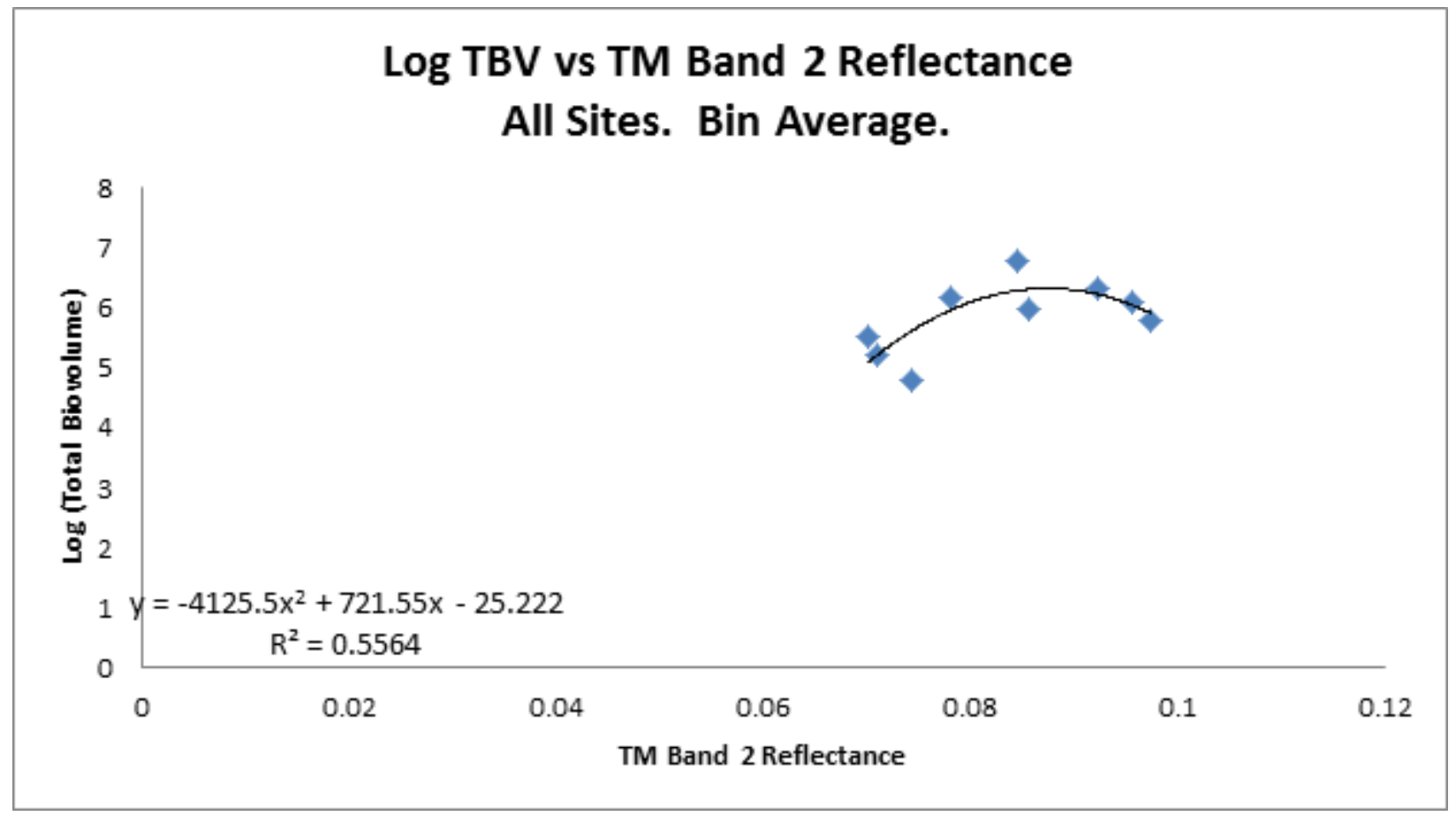

Figure 18 Binned Average for $\log _{10}(\mathrm{TBV})$ vs TM Band 2 Reflectance for All Sites. 


\section{Log BGBV vs TM Band 1 Reflectance \\ All Sites. Bin Average.}

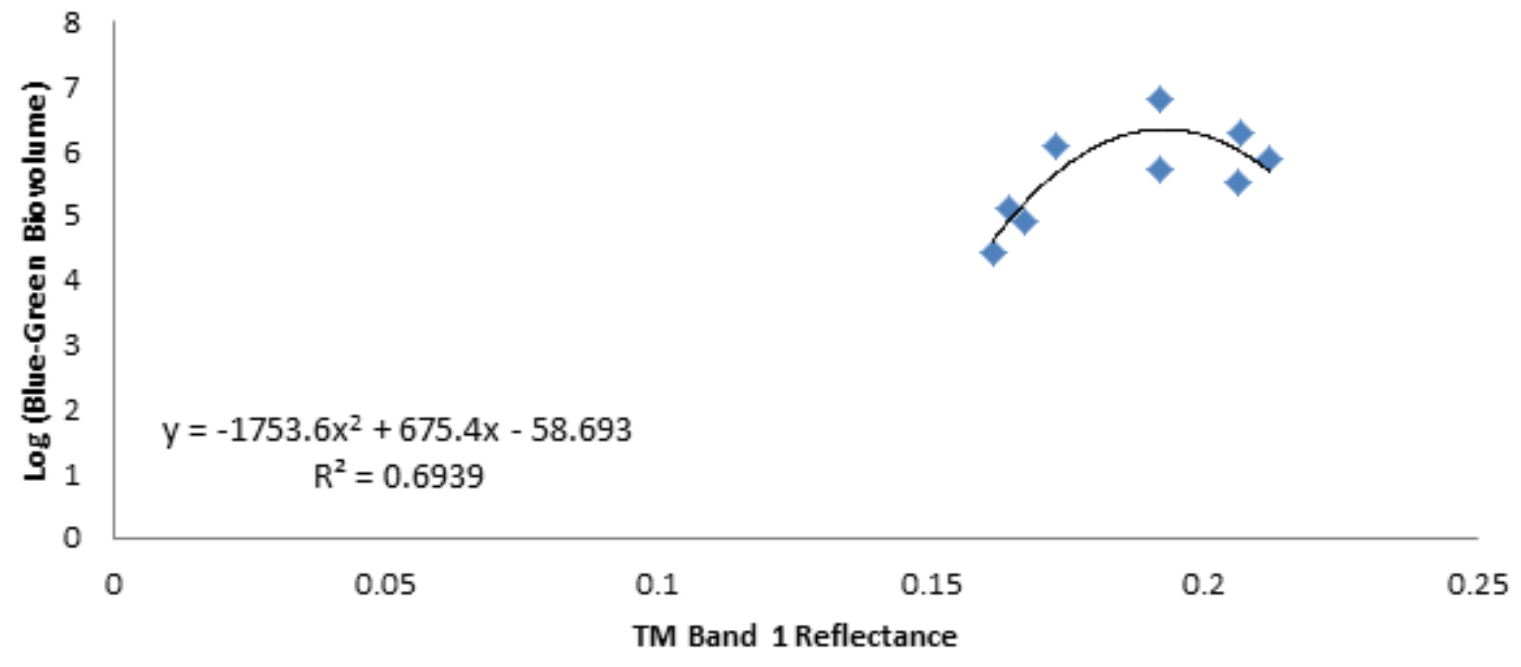

Figure 19 Binned Average for $\log _{10}(B G B V)$ vs TM Band 1 Reflectance for All Sites.

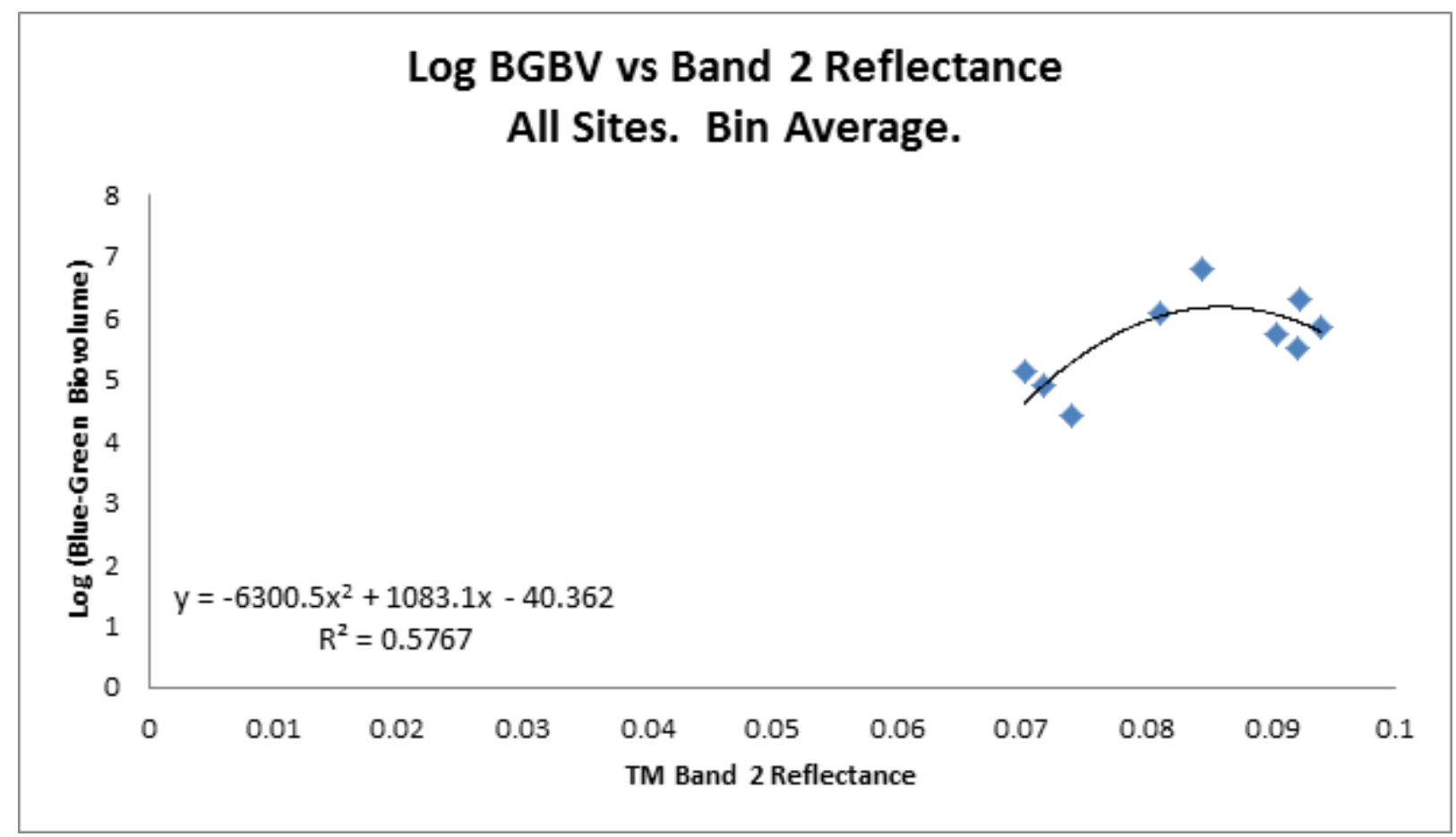

Figure $20 \quad$ Binned Average for $\log _{10}(B G B V)$ vs TM Band 2 Reflectance for All Sites.

A plot for a promising method for BGBV appears in Figure 21. The method takes a ratio of blue and green bands. The same method did not work well for TBV for any of the sites, including S3, which indicates it is more specific to blue-green biovolume. S3 is located on Templeton Arm, 
which has a freshwater inlet that introduces variable amount of sediment. This greater amount of sediment is potentially resulting in a more effective fit from traditional algal biovolume methods. More research is necessary.

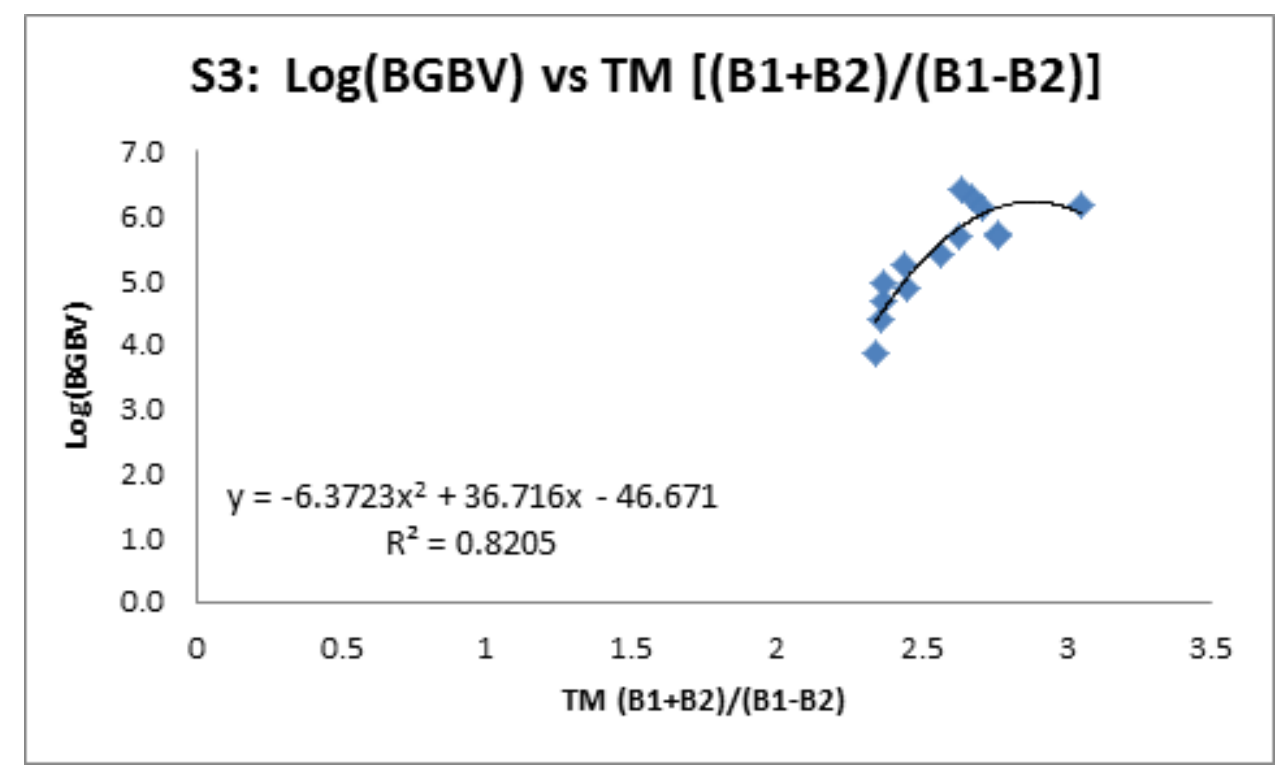

Figure 21

$\log _{10}(\mathrm{BGBV})$ vs TM $[(\mathrm{B} 1+\mathrm{B} 2) /(\mathrm{B} 1-\mathrm{B} 2)]$

Thematic Mapper has been used to monitor surface algae with the blue and green bands, but this method is not considered quantitative: However, methods for fitting Thematic Mapper satellite data to Chlorophyll concentration are numerous and quantitative in nature (Mayo, 1995, Sudheer, 2006). This study relied on satellite imagery from $+/-3$ days from the date of sampling on the lake.

The curves for Band 1 and for Band 2 for both plots of Chlorophyll a concentration versus TM Band 1 and Band 2 for Site S8 and Site N11 are shown in Figure 22 and Figure 23. Various methods for fitting Chlorophyll a concentration were applied to all sites, but no significant correlations were found. Band 1 and Band 2 yielded the best fit, so individual sites were used to fit the data. Band 2 yielded better fits for Chlorophyll a by site than did Band 1, but the results cannot be considered a usable predictive method for obtaining Chlorophyll a concentrations due to lack of data at lower values. It is unclear whether a polynomial model is a valid way to model the data. 


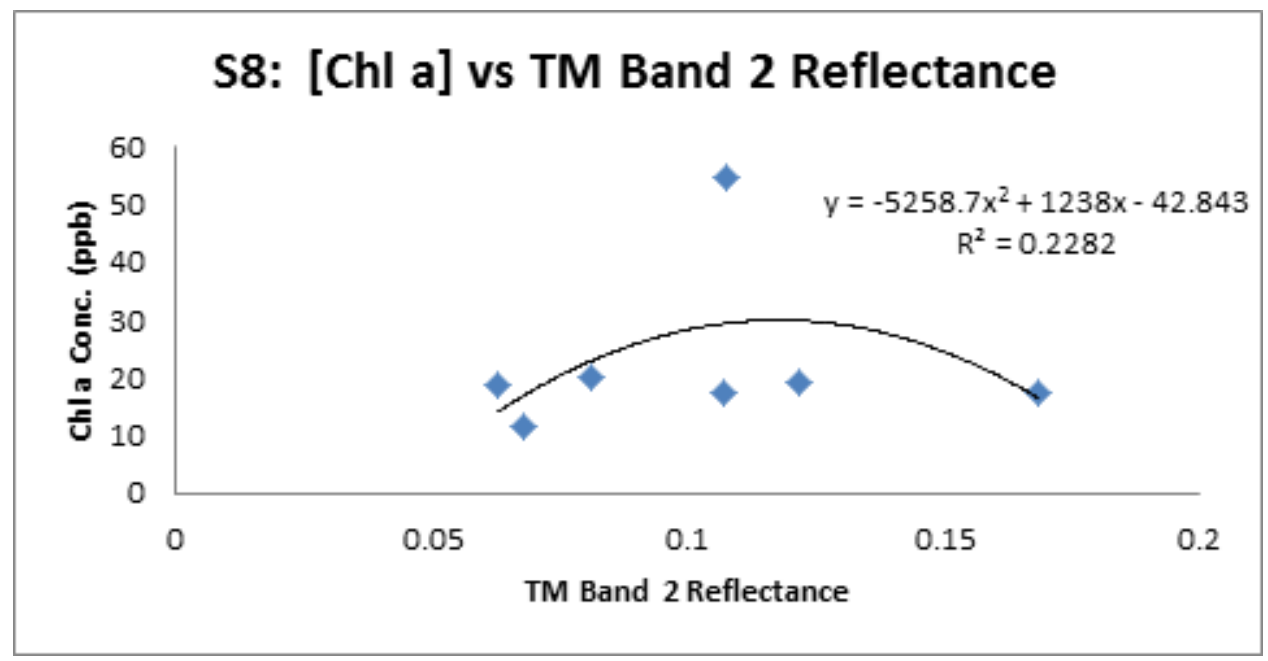

Figure $22 \quad$ Chlorophyll a concentration vs TM Band 2 Reflectance for Site S8.

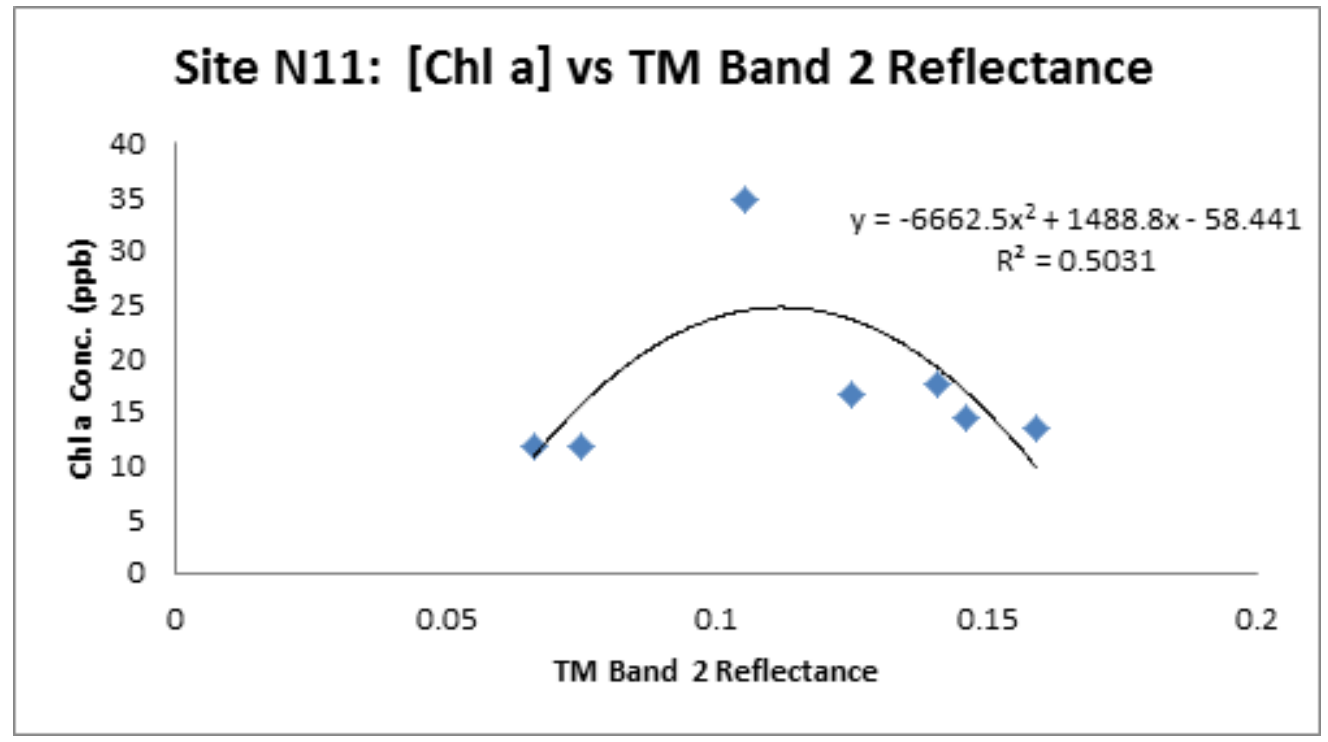

Figure 23 Chlorophyll a concentration vs TM Band 2 Reflectance for Site N11.

The Vincent algorithm was regressed to blue-green biovolume on Tenmile Lakes for $+/-3$ days from the date of the sample acquisition. Figure 24 represents a scatter plot of BGBV on Tenmile Lakes versus BGBV predicted from the Vincent TM algorithm using Phycocyanin as a proxy. While the $\mathrm{R}^{2}$ value is low, the data appears to be measuring a slight dependance between predicted and measured BGBV. However, the fit for TBV is better than the fit for BGBV which indicates the algorithm may be measuring a parameter other than Phycocyanin (BGBV). Another fact that supports the fit for TBV is that for the days used in the Vincent study the dominant species on Lake Erie was Microcystis. 


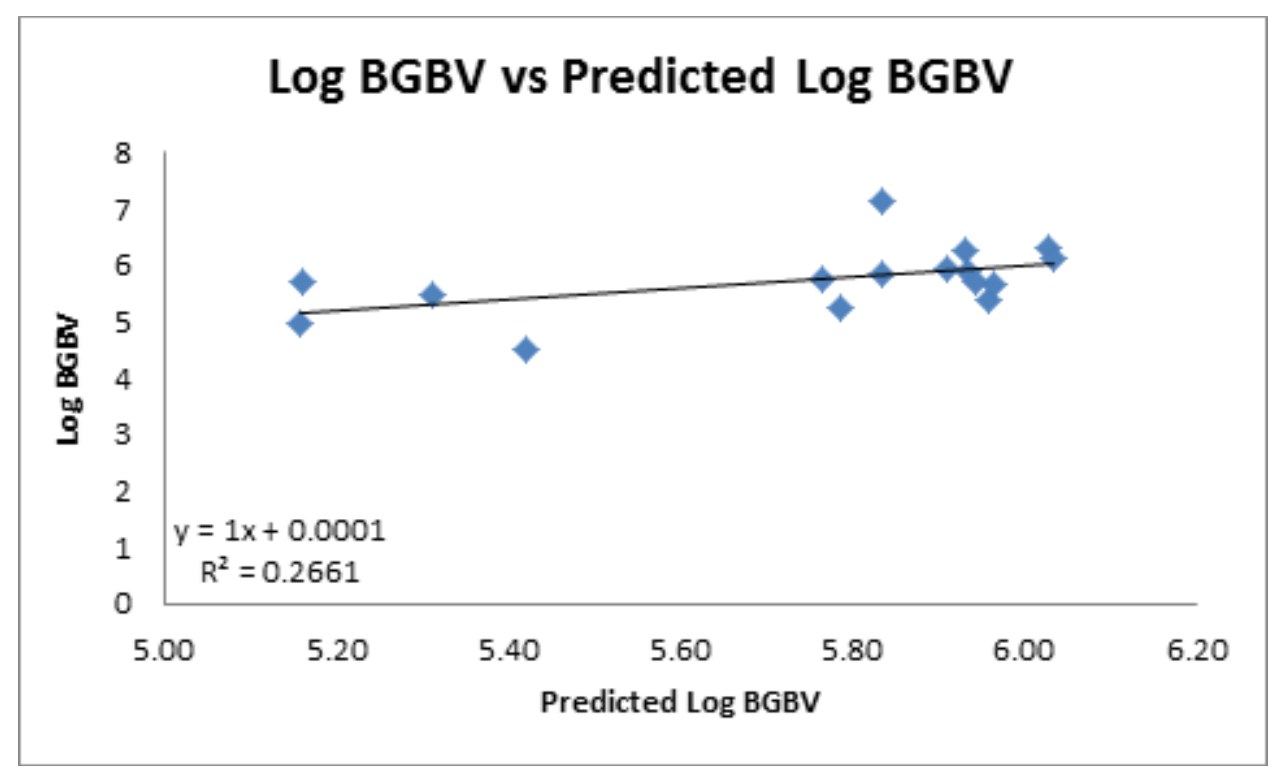

Figure 24 Figure 24: Plot of $\log _{10}(B G B V)$ versus Predicted $\log _{10}(B G B V)$.

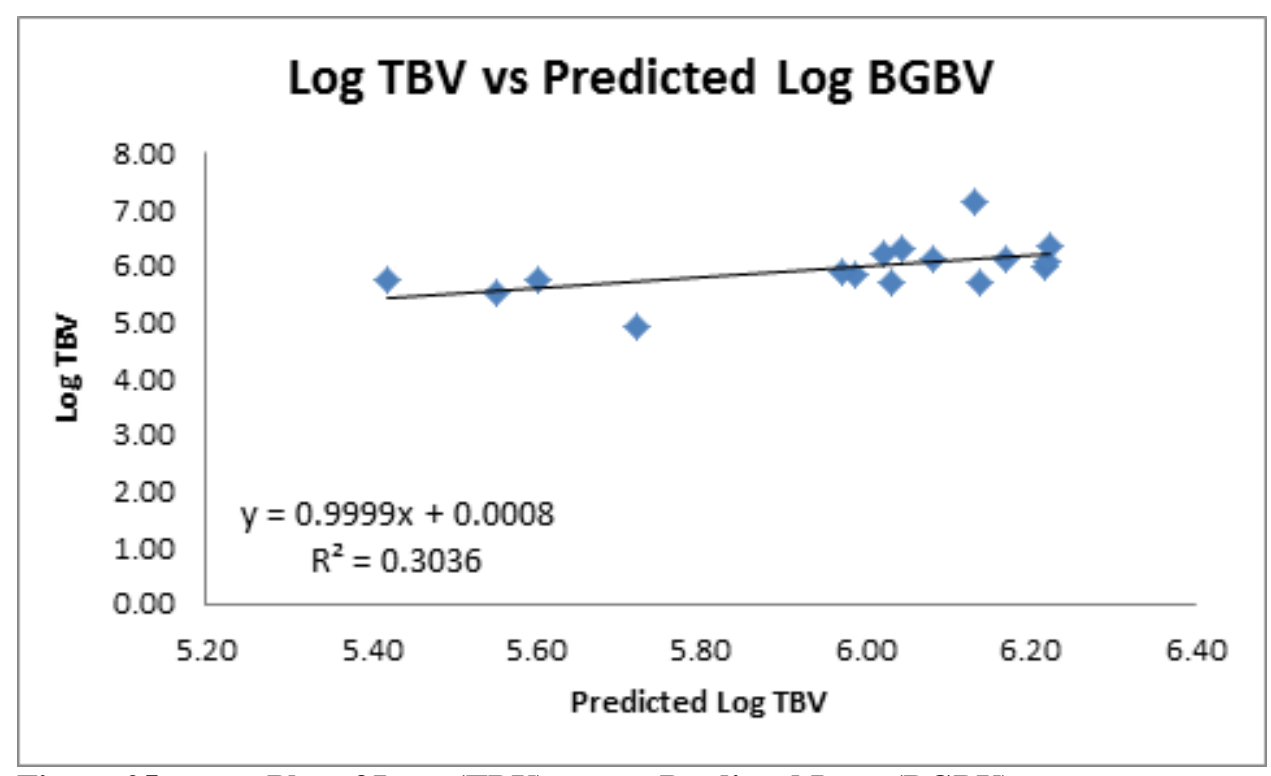

Figure $25 \quad$ Plot of $\log _{10}(\mathrm{TBV})$ versus Predicted $\log _{10}(\mathrm{BGBV})$.

\subsection{Comparison Between Satellite Data Digital Numbers and Radiance}

In this study, the differences between the use of Digital Numbers with a form of Dark Object Subtraction, the use of Radiance, and the use of Radiance with Dark Object Subtraction were investigated. Figure 26 shows a histogram of R-Squared values for Turbidity versus Band 1, Turbidity versus Band 2, and Turbidity versus Band 3 for all data points with no bin averaging. This same information is shown in Table 6. 


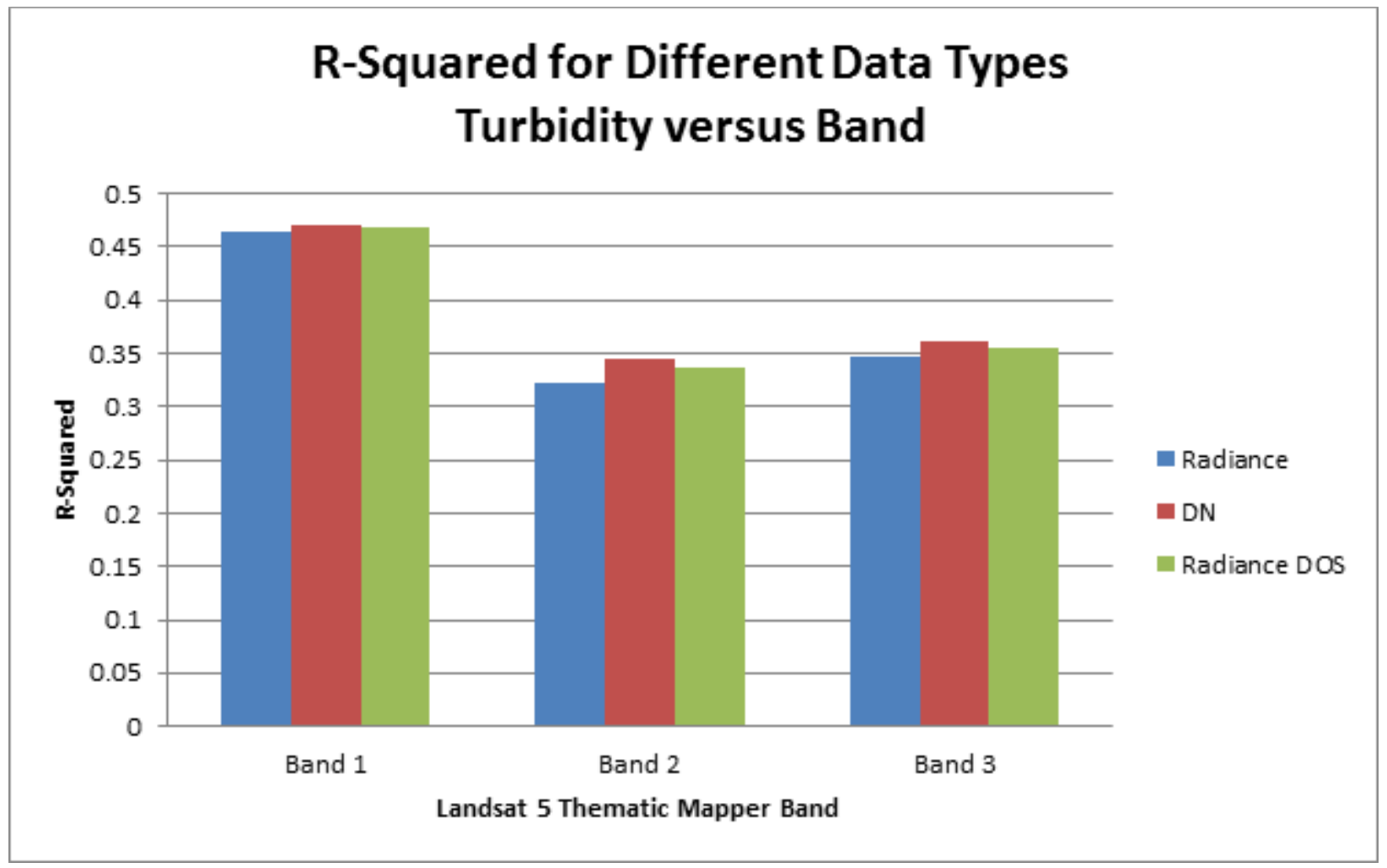

Figure $26 \quad$ R-Squared for Turbidity versus Band (1, 2, or 3) for different data types.

Table 6 Summary of R-Squared Values for Data Type for Turbidity versus Thematic Mapper Band.

\begin{tabular}{|l|c|c|c|}
\hline & \multicolumn{3}{|c|}{ R-Squared Values from Polynomial Best Fit } \\
\hline & Radiance & DN & Radiance DOS \\
\hline Band 1 & 0.4634 & 0.4701 & 0.4679 \\
\hline Band 2 & 0.3218 & 0.3449 & 0.3374 \\
\hline Band 3 & 0.3472 & 0.3607 & 0.3546 \\
\hline
\end{tabular}

Initial inspection of R-Squared values shows little difference between data types. The above histogram and summary are based on fitting the turbidity data to only one band at a time, however. The obvious best fit is for Band 1. Figure 27 shows a histogram for different types of data derived from Thematic Mapper DNs along with the DNs, so the histogram in Figure 27 shows values of the Digital Numbers as well as the values of Radiance and DOS Radiance. Radiance and DOS Radiance are derived from DNs. Visual inspection shows that the ratios between the bands for a given data type are not constant across bands. For example, the ratio of Band 1 to Band 3 is different for DNs than for Radiance, and the ratio of Band 1 to Band 4 is different for DNs than for Radiance, etc. This shows that data types are not interchangeable, but numerical training of data across data types is valid. An atmospheric correction becomes less 
critical when using cloud free days (Hadjimitsis et al., 2004). The similar values for radiance and DOS radiance illustrate this point.

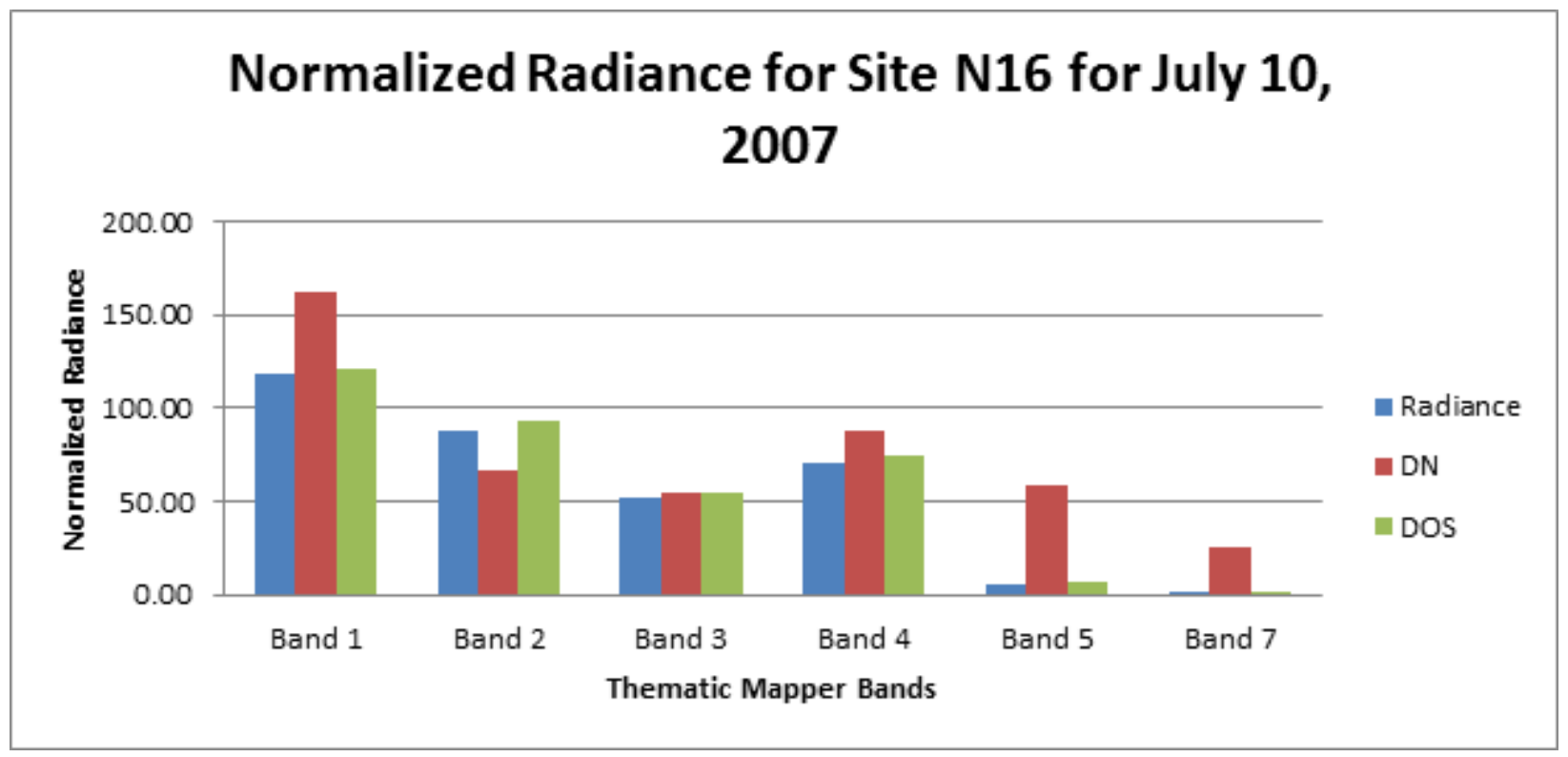

Figure $27 \quad$ Normalized Radiance for different data types for each band considered. 


\subsection{CONCLUSIONS}

The different data types, Digital Numbers, Radiance, and Dark Object Subtracted Radiance, possess different values, and band ratios from each type are not interchangeable. Within a given scene, radiance and dark object subtracted radiance are very close for cloud free days, and for Landsat 5, these depend on the amount of cloud cover, the time of year, and the sun elevation angle. Any study over time requires a corrected (normalized) radiance or a reflectance. The best fit to data from TM data is most often not linear, as is the case with many satellite instruments (Sudheer, 2006). The use of polynomial best fit equations in this study is not encouraged as it is unclear whether the polynomials are accurate.

Inland eutrophic freshwater lakes present the most difficult challenge in remote sensing (Kutser, 2009, Mayo, 1995, Ostlund, 2001, Ritchie, 1990, Sudheer, 2006, Tyler, 2006). On Tenmile Lakes, the only acceptable fit was for turbidity, and even turbidity values varied greatly by site. On algae dominated lakes, Band 1 (blue) provides the best fit to Turbidity. While a good correlation was obtained for Secchi depth to Turbidity and for Turbidity to TBV, BGBV, and $\mathrm{Chl}$ a, a direct fit to any of these with satellite data was inconclusive.

Curves for TBV, BGBV, and Chlorophyll a exhibited low $\mathrm{R}^{2}$, and though some relationship between satellite and in-situ data were found, they were deemed impracticable for predictive use. Possible reasons include lack of data at lower biovolumes or interference from other factors such as inverted sedimentation of the blue-green algae. While low levels of Chlorophyll a data did exist, it is well known that the presence of CDOM interferes with Chlorophyll a determination (Kutser, 2004). The variability in the values for TBV and BGBV from application of the best fit curve was equivalent to the ground data available, so it remains unclear whether a better fit would be obtained with a greater range in lake data. The quantification of biovolume, both TBV and BGBV, through Turbidity proved unsuccessful. Again, the margin of error is too great given the ground data available.

Application of the Vincent algorithm for PC to TBV and BGBV resulted in a significant correlation, but it is unclear what the algorithm is actually measuring. The algorithms for TM 
and ETM+ are also not interchangeable, even though NASA and USGS have taken steps to correlate the two different instruments. The variability of the predictions from this equation mirrored the variability of the data available.

Much can still be determined about the lake despite the lack of specific values for TBV, BGBV, and Chlorophyll a. Pseudo-color plots of the Turbidity, which correlates well to biovolume in the summer on Tenmile Lakes, indicate the regions of higher turbidity and biovolume. High levels with lack of flow could indicate surface vegetation, a migrated algal bloom, or an influx of nutrients from a leaking septic system, while low levels may indicate the channel location, low nutrients due to freshwater influx, or shallow water with visible sediment. 


\subsection{FUTURE DIRECTIONS:}

Because retro-adding couple bands to the visible spectrum of TM is not possible, most of the recommended future directions target ground sampling. A first suggestion would be to coordinate ground sampling with satellite overpass times. Continuously sampling instruments would fulfill this same need. In the future, a hyperspectral instrument with more bands and lower noise would allow the many light interacting substances (CDOM, turbidity, Chl a, and multiple algae species) to be separated. NASA's satellite EO-1, Earth Observer 1, with the instrument Hyperion is a possibility, even though the time between images is greater than that of Landsat. An example absorbance spectrum for water with a blue-green bacteria presence is shown in Figure 28.

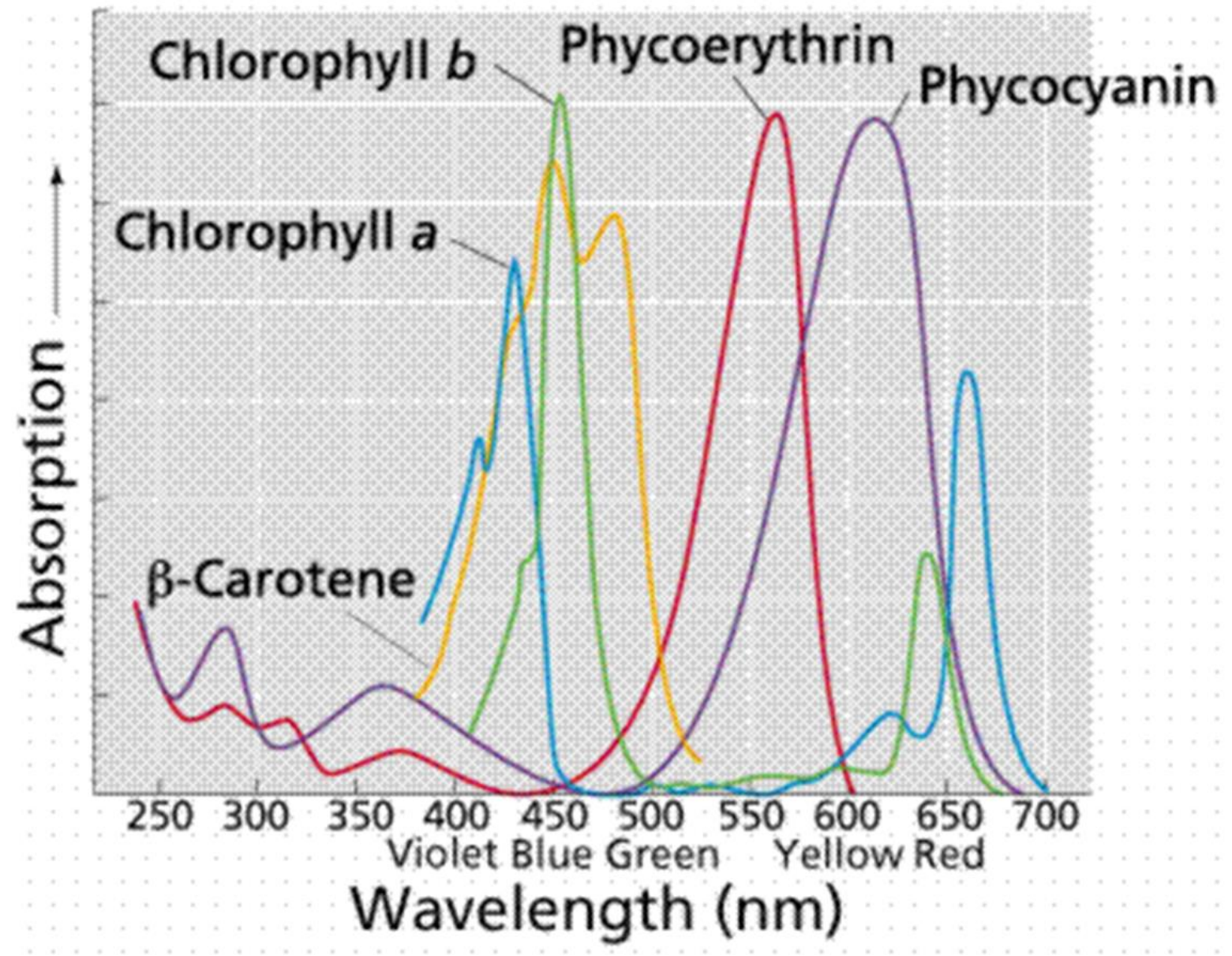

Figure 28 An example absorption spectrum for water with a cyanobacteria presence.

Sample collection could occur year round because the time between overpasses is greater, and a handheld spectrophotometer could be utilized for in-situ measurements of Chlorophyll a and 
Phycocyanin. Values for Suspended Particulate Inorganic/Organic Matter, SPIM/SPOM, would add a lot of value and are probably easier to determine than Turbidity when considering the difficulty in calibrating the Turbidity meter. 


\subsection{REFERENCES}

Atlas of Oregon Lakes, Portland State University, Accessed on April 20, 2014. http://aol.research.pdx.edu/lakes/17100304000657

Chander, G. and Markham, B., 2003, Revised Landsat-5 TM radiometric calibration procedures and postcalibration dynamic ranges. IEEE Transactions on Geoscience and Remote Sensing, 41:11, 2674-2678.

Chander, G., Markham, B. L., Barsi, J. A., 2007, Revised Landsat-5 Thematic Mapper

Radiometric Calibration. IEEE Geoscience and Remote Sensing Letters, 4:3, 490-494.

Hadjimitsis, D. G., Clayton, C. R. I., and Hope, V. S., 2004, An assessment of the effectiveness of atmospheric correction algorithms through remote sensing of some reservoirs. International Journal of Remote Sensing, 20, 3651-3674.

Harrington Jr., J. A., Schiebe, F. R., and Nix, J. F., 1992, Remote sensing of Lake Chicot, Arkansas: Monitoring suspended sediments, turbidity, and Secchi Depth with Landsat MSS data. Remote Sensing of Environment, 39, 15-27.

Hulley, Glynn C., Hook, Simon J., Schneider, Phillip, 2011, Optimized split-window coefficients for deriving surface temperatures from inland water bodies. Remote Sensing of Environment, 115, 3758-3769.

Kahru, M., Horstmann, U., and Rud, O., 1994, Satellite detection of increased cyanobacteria blooms in the Baltic Sea: natural fluctuation or ecosystem change?. Ambio, 23:8, 469-472.

Kutser, T., 2009, Passive optical remote sensing of cyanobacteria and other intense phytoplankton blooms in coastal and inland waters. International Journal of Remote Sensing, 30:17, 4401-4425.

Mayo, M., Gitelson, A., Yacobi, Y. Z., and Ben-Avraham, Z., 1995, Chlorophyll distribution in Lake Kinneret determined from Landsat Thematic Mapper data. International Journal of Remote Sensing, 16:1, 175-182.

NASA, Landsat 7 Science Data Users Handbook: http://landsathandbook.gsfc.nasa.gov/ Oregon Department of Environmental Quality, Water Quality Monitoring: Technical Guide Book, 1999.

Oregon Department of Environmental Quality, 1999, Water Quality Monitoring: Technical Guide Book. The Oregon Plan for Salmon and Watersheds.

Ostlund, C., Flink, P., Strombeck, N., Pierson, D., and Lindell, T., 2001, Mapping of the water quality of Lake Erken, Sweden, from imaging spectrometry and Landsat Thematic Mapper. The Science of the Total Environment, 268, 139-154. 
Palmer, C. M., 1969, A composite rating of algae tolerating organic pollution. Journal of Phycology, 5, 78-82.

Philpot, W., 2001, Cornell University, CEE615: Digital Image Processing, Part 3: Radiometric Correction, 3-1 to 3-6.

Ritchie, J. C., Cooper, C. M., and Schiebe, F. R., 1990, The relationship of MSS and TM digital data with suspended sediments, chlorophyll, and temperature in Moon Lake, Mississippi. Remote Sensing of Environment, 33, 137-148.

Simis, S. G., Steef, W. M. P., and Gons, H. J., 2005, Remote Sensing of the Cyanobacterial Pigment Phycocyanin in Turbid Inland Water. Limnology and Oceanography, 50:1, 237-245.

Sudheer, K. P., Chaubey, I., Garg, V., 2006, Lake water quality assessment from Landsat Thematic Mapper data using neural network: An approach to optimal band combination selection. Journal of the American Water Resources Association, December, 1683-1695.

Tenmile Lakes Basin Partnership (TLBP), Information from Richard Litts obtained between 2012 and 2014.

Turner, D., 2010, Remote sensing of Chlorophyll a concentrations to support the Deschutes Basin lake and reservoir TMDLs. Oregon Department of Environmental Quality.

Tyler, A. N., Svab, E., Preston, T., Presing, M., and Kovacs, W. A., 2006, Remote sensing of the water quality of shallow lakes: A mixture modelling approach to quantifying phytoplankton in water characterized by high-suspended sediment. International Journal of Remote Sensing, 27:8, 1521-1537.

Vincent, R. K., Qin, X., McKay, R. M. L., Miner, J., Czajkowski, K., Savino, J., and Bridgeman, T., 2004, Phycocyanin detection from Landsat TM data for mapping cyanobacterial blooms in Lake Erie. Remote Sensing of Environment, 89, 381-392. 